\begin{abstract}
UNIVERSIDADE DE SÃO PAULO
FACULDADE DE ODONTOLOGIA DE RIBEIRÃO PRETO PÓS-GRADUAÇÃO EM CIRURGIA E TRAUMATOLOGIA BUCO-MAXILO-FACIAL
\end{abstract}

Desenvolvimento do fenótipo osteogênico in vitro sobre diferentes nanotopografias de titânio funcionalizadas com o fator de crescimento GDF-5

Renan de Barros e Lima Bueno

Ribeirão Preto 
Renan de Barros e Lima Bueno

\title{
Desenvolvimento do fenótipo osteogênico in vitro sobre diferentes nanotopografias de titânio funcionalizadas com o fator de crescimento GDF-5
}

Dissertação apresentada à Faculdade de
Odontologia de Ribeirão Preto - USP,
como parte dos requisitos para obtenção
do título de Mestre em Cirurgia e
Traumatologia Buco-Maxilo-Facial.

Orientador: Paulo Tambasco de Oliveira

\author{
Ribeirão Preto
}


Autorizo a reprodução e divulgação total ou parcial deste trabalho, por qualquer meio convencional ou eletrônico, para fins de estudo e pesquisa, desde que citada a fonte.

FICHA CATALOGRÁFICA

Bueno, Renan de Barros e Lima

Desenvolvimento do fenótipo osteogênico in vitro sobre diferentes nanotopografias de titânio funcionalizadas com o fator de crescimento GDF-5. Ribeirão Preto, 2010.

74p.: il.; $30 \mathrm{~cm}$

Dissertação de Mestrado, apresentada à Faculdade de Odontologia de Ribeirão Preto da Universidade de São Paulo.

Área de concentração: Cirurgia e Traumatologia Buco-Maxilo-Facial.

Orientador: De Oliveira, Paulo Tambasco

1. Titânio. 2. Nanotopografia. 3. Osteogênese. 4. Fator de crescimento. 5. Cultura de células. 
Trabalho realizado no Laboratório de Cultura de Células da Faculdade de Odontologia de Ribeirão Preto da Universidade de São Paulo, com recursos da Fundação de Amparo à Pesquisa do Estado de São Paulo (FAPESP). 


\section{FOLHA DE APROVAÇÃO}

Renan de Barros e Lima Bueno

Desenvolvimento do fenótipo osteogênico in vitro sobre diferentes nanotopografias de titânio funcionalizadas com o fator de crescimento GDF-5.

Dissertação apresentada à Faculdade de Odontologia de Ribeirão Preto da Universidade de São Paulo para obtenção do título de Mestre.

Área de Concentração: Cirurgia e Traumatologia Buco-Maxilo-Facial

Aprovado em: / 2010

\section{Banca Examinadora}

Prof. Dr. Instituição: Assinatura:

Prof. Dr. Instituição: Assinatura:

Prof. Dr. Instituição: Assinatura: 
Dedico este trabalho aos meus pais, João Batista e Eline, grande parte desta conquista devo a vocês. É incomensurável a gratidão e o amor que tenho por vocês.

Aos meus irmãos Marcel e Rafaela, pelo companheirismo e amizade Estamos sempre juntos. Amo vocês!

A toda minha inestimável família de que tenho a honra de fazer parte.

À minha namorada Ana Paula, pela lealdade, apoio, compreensão e carinho em todos esses anos. Amo você! 
À Universidade de São Paulo, representada pelo reitor Prof. Dr. João Grandino Rodas.

À Faculdade de Odontologia de Ribeirão Preto - USP, representada pelo diretor Prof. Dr. Osvaldo Luiz Bezzon.

À Fundação de Amparo à Pesquisa do Estado de São Paulo (FAPESP), pela bolsa de mestrado concedida.

Ao Prof. Dr. Adalberto Luiz Rosa, da Faculdade de Odontologia de Ribeirão Preto USP, e ao Prof. Dr. Antonio Nanci, do Laboratory for the Study of Calcified Tissues and Biomaterials (Université de Montréal), pela colaboração neste trabalho.

Ao meu orientador, Prof. Dr. Paulo Tambasco de Oliveira, grande pessoa, orientador e amigo. Fiquei muito honrado por ter trabalhado com um dos melhores pesquisadores deste país. Você me ensinou muito, mestre!

Aos docentes do curso de Mestrado em Cirurgia e Traumatologia Buco-Maxilo-Facial da Faculdade de Odontologia de Ribeirão Preto - USP, Prof. Dr. Adalberto Luiz Rosa, Prof. Dr. Alexandre Elias Trivellato, Prof. Dr. Cássio Edvard Sverzut, Prof. Dr. Luiz Antônio Salata, Prof. Dr. Samuel Porfírio Xavier, Prof. Dr. Valdemar Mallet da Rocha Barros, pelo grande aprendizado e pela boa convivência.

Aos amigos do curso de mestrado de Cirurgia: Ana, Luciana, Marcelo, Michel, Rogério, Patrício e Gustavo; grandes profissionais e amigos que levarei para o resto da minha vida.

Às minhas grandes amigas do curso de mestrado em Periodontia: Luciana, Ingrid e Karina, considero vocês como parte integrante da minha turma de mestrado. Boa sorte em suas caminhadas profissionais.

Aos amigos da residência Marcão, André, Fernando e Eduardo, pessoas que também foram importantes nestes anos de mestrado.

Aos amigos Larissa de Castro e Lucas Novaes. Pessoas que me ajudaram muito no Laboratório de Cultura de Células. Muito obrigado pela paciência e bondade, sem vocês ficaria muito mais difícil meu trabalho. 
Ao Roger Rodrigo Fernandes, pela imensa e indispensável ajuda durante os experimentos no laboratório. Pessoa confiável, competente e honesta. Grande ser humano.

À Karen Vasconcelos, por sua contribuição ao desenvolvimento do nosso trabalho.

À Fabíola Singaretti de Oliveira, pela orientação e ajuda na realização dos experimentos no Laboratório de Biologia Molecular.

Aos professores da Faculdade de Odontologia de Bauru - USP, especialmente Prof. Dr. Eduardo Sant'Ana e Prof. Dr. Osny Ferreira Júnior, e também aos Drs. Fernando Giglio e Luis Fernando Sant'Ana, pelos ensinamentos fundamentais no começo da minha carreira profissional.

Aos professores da Faculdade de Odontologia de Araçatuba - UNESP, especialmente Prof. Dr. Idelmo Rangel Garcia Junior, Profa. Dra. Alessandra Marcondes Aranega, Profa. Dra. Cristiane Mara Ruiz de Sousa Fattah e Prof. Dr. Osvaldo Magro Filho, pela oportunidade de meu estágio.

Aos meus grandes e inesquecíveis amigos da Faculdade de Odontologia de Bauru- em especial ao Danilo, Daniel, Ivan, Kléber, Wiliam, Rodrigo e Eduardo.

Aos meus grandes e fiéis amigos da cidade de Araçatuba, esta conquista devo a vocês também.

Às secretárias do Departamento de Cirurgia e Traumatologia Buco-Maxilo-Facial e Periodontia da FORP-USP, Dulce Negretti e Tatiana Fernandes.

Aos demais funcionários da FORP-USP, que em algum momento me ajudaram na realização desse trabalho. 


\section{LISTA DE ABREVIATURAS E SIGLAS}

Ti: titânio

$\mu \mathrm{m}:$ micrometro

$\mathrm{nm}$ : nanometro

SLA: sandblasted and acid-etched

modSLA: SLA modificada

GDF-5: fator de crescimento e diferenciação 5

TGF- $\beta$ : fator de crescimento transformante $\beta$

BMP: proteínas morfogenéticas ósseas

PRP: plasma rico em plaquetas

TGF- $\beta 1$ : fator de crescimento transformante $\beta 1$

TGF- $\beta 2$ : fator de crescimento transformante $\beta 2$

MEC: matriz extracelular

ng/mL: nanocrograma/mililitro

Real-time PCR: reação em cadeia de polimerase em tempo real

ALP: fosfatase alcalina

MEV: microscopia eletrônica de varredura

MTT: $\{$ brometo de [3-(4,5-dimetiltiazol-2-il)-2,5-difeniltetrazolio]\}

OPN: osteopontina

BSP: sialoproteína óssea

RUNX2: fator de transcrição relacionado ao runt tipo 2

ARS: vermelho de Alizarina

RNAm: ácido ribonucleico mensageiro 
mm: milímetro

$\mathrm{kV}$ : kilovolt

${ }^{\circ} \mathrm{C}$ : grau Celsius

CEUA: comissão de ética no uso de animais

a-MEM: meio essencial mínimo, modificação a

mM: milimolar

$\mu \mathrm{g} / \mathrm{mL}:$ micrograma/mililitro

$\mathrm{CO}_{2}$ : gás carbônico

DAPI: 4',6-diamidino-2-phenylindole, dihydrochloride

DNA: ácido desoxirribonucleico

h: hora

M: molar

$\mathrm{mg} / \mathrm{mL}$ : miligrama/mililitro

PBS: solução tampão salina de fosfato (Phosphate buffered saline)

$\mathrm{mL}$ : mililitro

$\mu L:$ microlitro

$\mathrm{HCl}$ : ácido clorídrico

min: minuto

Ki-67: antígeno nuclear

EDTA: ácido etilenodiamino tetra-acético

PB: solução tampão fosfato (Phosphate buffered)

TA: temperatura ambiente

nM: nanomolar

GAPDH: D-glyceraldehyde-3-phosphate dehydrogenase

cDNA: ácido desoxirribonucleico complementar 
$\mu g:$ micrograma

DEPC: água Milli-Q tratada com dietilpirocarbonato

ng: nanograma

Ct: ciclo limiar (cicle threshold)

$\mathrm{Na}_{2} \mathrm{CO}_{3}$ : carbonato de sódio

$\mathrm{NaOH}$ : hidróxido de sódio

$\mu \mathrm{M}$ : micromolar

s: segundo

g: unidade de aceleração, aproximadamente igual a 9,8 m/s

$\mathrm{H}_{2} \mathrm{SO}_{4}$ : ácido sulfúrico

$\mathrm{H}_{2} \mathrm{O}_{2}$ : peróxido de hidrogênio

RMS: rugosidade média quadrática

IRRAS: espectroscopia de reflexão-absorção no infravermelho 


\section{JUSTIFICATIVA:}

Estratégias para o desenvolvimento de biomateriais que promovam eventos biológicos específicos na região interfacial durante o processo de reparo incluem modificações de sua superfície, entre as quais composição química, energia/molhamento e topografia, consideradas determinantes em sua interação com células e proteínas plasmáticas e da matriz extracelular (KIESWETTER et al. 1996; BRUNSKI et al. 2000).

Em relação aos aspectos topográficos, o desenvolvimento de superfícies de titânio (Ti) e ligas de Ti estruturadas na microescala $(1-10 \mu \mathrm{m})$, sobretudo na década passada, resultou na comercialização de implantes dentais e ortopédicos com superfícies que favorecem a osseointegração. Estudos in vitro e in vivo demonstraram que esse fenômeno poderia ser atribuído a alguns eventos biológicos, entre os quais: 1) formação de coágulo de fibrina e ativação de plaquetas mais precoces (DAVIES 1998; PARK \& DAVIES 2000; PARK et al. 2001; DI IORIO et al. 2005), 2) microambiente tridimensional adequado à formação óssea (MATSUZAKA et al. 2003), 3) aumento da síntese e secreção de fatores de crescimento com efeitos sobre as células do tecido ósseo (BOYAN et al. 2003) e 4) redução da atividade osteoclástica controlada por fatores secretados por osteoblastos (LOSSDORFER et al. 2004). Estudos experimentais revelaram que associações de microtopografias com topografias na escala submicrométrica, entre 100-150 nm e menores do que 1 um (ROSEI 2004), promovem efeitos de sinergismo nas respostas teciduais, com aumento da proliferação celular (ZINGER et al. 2004; TAN \& SALTZMAN 2004), de atividades celulares (TAN \& SALTZMAN 2004), da 
expressão de marcadores da diferenciação osteoblástica (MENDONÇA et al. 2010) e da formação de nódulos de matriz mineralizada in vitro (WIELAND et al. 2005).

Com o advento da Nanotecnologia, tem sido crescente a busca pelo desenvolvimento e aprimoramento de superfícies de biomateriais nanoestruturadas, apresentando aspectos topográficos de dimensões que variam entre 1 e 100-150 nm (ROSEl 2004). Essa tendência fundamenta-se em estudos pioneiros que demonstraram que aspectos topográficos na nanoescala de diferentes biomateriais afetam os processos de adsorção de proteínas, adesão celular, morfologia, diferenciação celular e produção e secreção de moléculas da matriz extracelular, associados a vários tipos celulares (CURTIS \& WILKINSON 1999; DALBY et al. 2006; VETRONE et al. 2009; RICHERT et al. 2010). De fato, é na escala nanométrica que ocorrem fenômenos celulares e teciduais importantes. As células se desenvolvem e migram em matrizes extracelulares nanoestruturadas (FLEMMING et al. 1999; SMITH \& MA 2004), a matriz óssea em que os implantes são colocados apresenta nanotopografia intrínseca (HASSENKAM et al. 2004) e as complexas interações célula-matriz-substrato, associadas aos eventos de sinalização celular por meio de transdução de sinais, ocorrem na nanoescala (MAHESHWARI et al. 2000; SIEBERS et al. 2005). Há evidências experimentais de que aspectos nanotopográficos de biomateriais estimulam a formação óssea em períodos iniciais pós-implantação (ELLINGSEN et al. 2004; BERGLUNDH et al. 2007; MENDES et al. 2007; MEIRELLES et al. 2007; MEIRELLES et al. 2008). Esses aspectos vêm despertando um crescente interesse da comunidade científica visando à compreensão dos efeitos biológicos de nanotopografias sobre diferentes células e tecidos, incluindo o tecido ósseo (STEVENS \& GEORGE 2005; VARIOLA et al. 2009). 
Diferentes métodos podem ser empregados para se criarem nanotopografias em Ti, entre os quais os métodos químicos (revisado por MENDONÇA et al. 2008). Em 1998, NANCl et al. desenvolveram um método simples e de baixo custo para obter superfícies de Ti com nanotopografia, baseado em desoxidação e reoxidação controladas, por meio de condicionamento químico com solução de $\mathrm{H}_{2} \mathrm{SO}_{4} / \mathrm{H}_{2} \mathrm{O}_{2}$. Os resultados experimentais revelaram que esse tratamento de superfície resulta na formação de nanotopografia caracterizada por rede de nanocavidades, além de proporcionar o aumento de sítios disponíveis para a subseqüente imobilização covalente de moléculas bioativas, visando ao desenvolvimento de superfícies biomiméticas e/ou bioativas. Nesses experimentos, os autores demonstraram que o processo para a imobilização de fosfatase alcalina e albumina não modificava sua atividade enzimática e antigenicidade, respectivamente.

Em 2004, DE OLIVEIRA \& NANCI demonstraram que esse tratamento químico, realizado por períodos de 1 e 4 horas em discos de liga de $\mathrm{Ti}$ e Ti, respectivamente, estimula eventos iniciais de culturas primárias de células osteogênicas, aumentando a expressão citoplasmática e extracelular das proteínas matricelulares BSP e OPN. Nesse estudo, os autores indicavam a necessidade de avaliar se o aumento da expressão dessas proteínas matricelulares teria algum impacto na proporção de área total de formação de matriz mineralizada in vitro.

Dados os resultados biológicos iniciais relevantes e promissores, $\mathrm{YI}$ et al. (2006) caracterizaram por vários métodos a superfície de Ti com nanotopografia criada pelo condicionamento com $\mathrm{H}_{2} \mathrm{SO}_{4} / \mathrm{H}_{2} \mathrm{O}_{2}$, os quais revelaram: 1) que era formada por camada de $\mathrm{TiO}_{2}$ puro em sua maior parte, com espessura variando de 32 a $40 \mathrm{~nm}, 2$ ) principalmente de fase amorfa e 3) altamente porosa, com nanocavidades de diâmetros de $22 \pm 7 \mathrm{~nm}$. 
Estudando vários parâmetros associados ao desenvolvimento do fenótipo osteogênico in vitro, DE OLIVEIRA et al. (2007) observaram que culturas primárias osteogênicas exibiam aceleração e/ou aumento de formações nodulares de matriz mineralizada sobre nanotopografia de $\mathrm{Ti}$, com aumento do conteúdo de proteína total, e atividade de fosfatase alcalina com picos mais precoces se comparados aos do grupo controle. Além dos efeitos diretos da nanotopografia sobre a atividade celular e tecidual, os autores consideraram o aumento significativo da hidrofilicidade um fator que pudesse contribuir para a ocorrência desses efeitos biológicos. De fato, tem sido demonstrado que alterações no molhamento/energia de superfície de biomateriais podem alterar os processos de adsorção de proteínas (ROACH 2005), adesão e espraiamento celulares (LIM et al. 2005; WEBB et al. 1998; SCHWARTZ FO et al. 2007), e promover o aumento da atividade osteoblástica (BUSER et al. 2004; SCHWARTZ FO et al. 2007). A aceleração no processo de osseointegração exibida pela superfície SLAactive (originalmente conhecida como modSLA; Straumann Holding AG, Basel, Suíça) é atribuída à natureza altamente hidrofílica de sua microtopografia, modificada quimicamente (BUSER et al. 2004; RUPP et al. 2006).

As superfícies de biomateriais podem ser modificadas por métodos bioquímicos, visando à disponibilização de proteínas, enzimas ou peptídios bioativos para a indução de respostas celulares e teciduais específicas na região interfacial. $\mathrm{Na}$ área de desenvolvimento de implantes metálicos, utilizam-se estratégias de funcionalização de superfícies com peptídios/proteínas que apresentam efeitos conhecidos nas diferentes fases do processo de formação óssea (PULEO \& NANCI 1999; GARCIA \& REYES 2005; MORRA 2006; SHEKARAN \& GARCIA 2010; BEUTNER et al. 2010). O fator de crescimento e diferenciação 5 (GDF-5, ou 
Cartilage-Derived Morphogenetic Protein-1, CDMP-1) é uma proteína da superfamília do fator de crescimento transformante $\beta$ (TGF- $\beta$ ) que desempenha papel fundamental no desenvolvimento do esqueleto cartilaginoso (FRANCIS-WEST et al. 1999) e ósseo (KUNIYASU et al. 2003; YOSHIMOTO et al. 2006). Em relação ao esqueleto cartilaginoso, o GDF-5 pode modular os estágios iniciais da condrogênese (condensações mesenquimais), aumentando a adesão celular e estimular a proliferação de condrócitos (FRANCIS-WEST et al. 1999). Na biologia óssea, o mecanismo de ação do GDF-5 assemelha-se ao de proteínas morfogenéticas ósseas (BMPs; SPIRO et al. 2000), induzindo a formação ectópica de tecido ósseo (KUNIYASU et al. 2003; YOSHIMOTO et al. 2006). Em células osteogênicas de calvária in vitro, o GDF-5 estimula a migração e proliferação celular, bem como a produção de matriz extracelular (NAKAMURA et al. 2003; YOSHIMOTO et al. 2006). Em estudo publicado por nosso grupo, culturas de células osteoblásticas humanas que exibiam inibição do fenótipo osteogênico por ação de coquetel de fatores de crescimento e proteínas típicos de plasma rico em plaquetas (PRP), incluindo TGF- $\beta 1$ e TGF- $\beta 2$, quando expostas a $20 \mathrm{ng} / \mathrm{mL}$ de GDF-5 recombinante humano, mostraram aumento da expressão de ALP e RUNX2 (DE OLIVEIRA et al. 2008). Apesar de o GDF-5 estimular a formação de cartilagem e osso, admite-se que os efeitos indutores de formação óssea ocorram mais acentuadamente em sítios ósseos (KUNIYASU et al. 2003). Nesse sentido, a estratégia de disponibilizar GDF-5 na interface implante-osso poderia resultar em benefícios para o processo de osseointegração. 


\section{REFERÊNCIAS BIBLIOGRÁFICAS:}

Beutner R, Michael J, Schwenzer B, Scharnweber D. Biological nanofunctionalization of titanium-based biomaterial surfaces: a flexible toolbox. J R Soc Interface 2010;7:S93-S105.

Berglundh T, Abrahamsson I, Albouy JP, Lindhe J. Bone healing at implants with a fluoride-modified surface: an experimental study in dogs. Clin Oral Implants Res 2007;18:147-152.

Boyan BD, Lossdorfer S, Wang L, Zhao G, Lohmann CH, Cochran DL, Schwartz Z. Osteoblasts generate an osteogenic microenvironment when grown on surfaces with rough microtopographies. Eur Cells Mater 2003;6:22-27.

Brunski JB, Puleo DA, Nanci A. Biomaterials and biomechanics of oral and maxillofacial implants: current status and future developments. Int J Oral Maxillofac Implants 2000;15:15-46.

Buser D, Broggini N, Wieland M, Schenk RK, Denzer AJ, Cochran DL, Hoffmann B, Lussi A, Steinemann SG. Enhanced bone apposition to a chemically modified SLA titanium surface. J Dent Res. 2004;83:529-533.

Curtis A, Wilkinson C. New depths in cell behaviour: reactions of cells to nanotopography. Biochem Soc Symp 1999;65:15-26.

Dalby MJ, McCloy D, Robertson M, Wilkinson CD, Oreffo RO. Osteoprogenitor response to defined topographies with nanoscale depths. Biomaterials 2006;27:1306-1315.

Davies JE. Mechanisms of endosseous integration. Int J Prosthodont 1998;11:391401.

De Oliveira PT, Nanci A. Nanotexturing of titanium-based surfaces upregulates expression of bone sialoprotein and osteopontin by cultured osteogenic cells. Biomaterials 2004;25:403-413.

De Oliveira PT, Zalzal SF, Beloti MM, Rosa AL, Nanci A. Enhancement of in vitro osteogenesis on titanium by chemically produced nanotopography. J Biomed Mater Res A 2007;80:554-564.

De Oliveira PT, de Oliva MA, Maximiano WM, Sebastião KE, Crippa GE, Ciancaglini $\mathrm{P}$, Beloti MM, Nanci A, Rosa AL. Effects of a mixture of growth factors and proteins on the development of the osteogenic phenotype in human alveolar bone cell cultures. J Histochem Cytochem 2008;56:629-638.

Di lorio D, Traini T, Degidi M, Caputi S, Neugebauer J, Piattelli A. Quantitative evaluation of the fibrin clot extension on different implant surfaces: an in vitro study. J Biomed Mater Res B Appl Biomater 2005;74:636-642. 
Ellingsen JE, Johansson CB, Wennerberg A, Holmen A. Improved retentionand bone-to-implant contact with fluoride-modified titanium implants. Int J Oral Maxillofac Implants 2004;19:659-666.

Flemming RG, Murphy CJ, Abrams GA, Goodman SL, Nealey PF. Effects of synthetic micro- and nano-structured surfaces on cell behavior. Biomaterials 1999;20:573-588.

Francis-West P, Abdelfattah A, Chen P, Allen C, Parish J, Ladher R, Allen S, MacPherson S, Luyten F, Archer C. Mechanisms of GDF-5 action during skeletal development. Development 1999;126:1305-1315.

Garcia AJ, Reyes CD. Bio-adhesive surfaces to promote osteoblast differentiation and bone formation. J Dent Res 2005;84:407-413.

Hassenkam T, Fantner GE, Cutroni JA, Weaver JC, Morse DE, Hansma PK. Highresolution AFM imaging of intact and fractured trabecular bone. Bone 2004;35:4-10.

Kieswetter K, Schwartz Z, Dean DD, Boyan BD. The role of implant surface characteristics in the healing of bone. Crit Rev Oral Biol Med 1996;7:329-345.

Kuniyasu H, Hirose Y, Ochi M, Yajima A, Sakaguchi K, Murata M, Pohl J. Bone augmentation using rhGDF-5-collagen composite. Clin Oral Implants Res 2003;14:490-499.

Lim JY, Hansen JC, Siedlecki CA, Hengstebeck RW, Cheng J, Winograd N, Donahue HJ. Osteoblast adhesion on poly(L-lactic acid)/polystyrene demixed thin film blends: effect of nanotopography, surface chemistry, and wettability. Biomacromolecules 2005;6:3319-3327.

Lossdorfer S, Schwartz Z, Wang L, Lohmann CH, Turner JD, Wieland M, Cochran $\mathrm{DL}$, Boyan BD. Microrough implant surface topographies increase osteogenesis by reducing osteoclast formation and activity. J Biomed Mater Res A 2004;3:361-369.

Maheshwari G, Brown G, Lauffenburger DA, Wells A, Griffith LG. Cell adhesion and motility depend on nanoscale RGD clustering. J Cell Sci 2000;113:1677-1686.

Matsuzaka K, Frank Walboomers X, Yoshinari M, Inoue T, Jansen JA. The attachment and growth behavior of osteoblast-like cells on microtextured surfaces. Biomaterials 2003;24:2711-2719.

Meirelles L, Arvidsson A, Albrektsson T, Wennerberg A. Increased bone formation to unstable nano rough titanium implants. Clin Oral Implants Res 2007;18:326-332.

Meirelles L, Melin L, Peltola T, Kjellin P, Kangasniemi I, Currie F, Andersson M, Albrektsson T, Wennerberg A.. Effect of hydroxyapatite and titania nanostructures on early in vivo bone response. Clin Implant Dent Relat Res 2008;4:245-254.

Mendes VC, Moineddin R, Davies JE. The effect of discrete calcium phosphate nanocrystals on bone-bonding to titanium surfaces. Biomaterials 2007;28:4748-4755. 
Mendonça G, Mendonça DB, Aragão FJ, Cooper LF. Advancing dental implant surface technology - From micron- to nanotopography. Biomaterials 2008; 28:38223835.

Mendonça G, Mendonça DB, Aragão FJ, Cooper LF. The combination of micron and nanotopography by $\mathrm{H}_{2} \mathrm{SO}_{4} / \mathrm{H}_{2} \mathrm{O}_{2}$ treatment and its effects on osteoblast-specific gene expression of hMSCs. J Biomed Mater Res A 2010;94:169-179.

Morra M. Biochemical modification of titanium surfaces: peptides and ECM proteins. Eur Cell Mater 2006;12:1-15.

Nakamura T, Yamamoto M, Tamura M, Izumi Y. Effects of growth/differentiation factor-5 on human periodontal ligament cells. J Periodontal Res 2003;38:597-605.

Nanci A, Wuest JD, Peru L, Brunet P, Sharma V, Zalzal S, McKee MD. Chemical modification of titanium surfaces for covalent attachment of biological molecules. J Biomed Mater Res1998;40:324-335.

Park JY, Davies JE. Red blood cell and platelet interactions with titanium implant surfaces. Clin Oral Implants Res 2000;11:530-539.

Park JY, Gemmell CH, Davies JE. Platelet interactions with titanium: modulation of platelet activity by surface topography. Biomaterials 2001;22:2671-2682.

Puleo DA, Nanci A. Understanding and controlling the bone-implant interface. Biomaterials 1999;20:2311-2321.

Richert L, Variola F, Rosei F, Wuest J, Nanci A. Adsorption of proteins on nanoporous Ti surfaces. Surf Sci 2010;604:1445-1451.

Roach P, Farrar D, Perry CC. Interpretation of protein adsorption: surface-induced conformational changes. J Am Chem Soc 2005;127:8168-8173.

Rosei F. Nanostructured surfaces: challenges and frontiers in nanotechnology. J Physics: Condensed Matter 2004;16:1373-1436.

Rupp F, Scheideler L, Olshanska N, de Wild M, Wieland M, Geis-Gerstorfer J. Enhancing surface free energy and hydrophilicity through chemical modification of microstructured titanium implant surfaces. J Biomed Mater Res A 2006;76:323-334.

Schwartz Fo HO, Novaes AB Jr, de Castro LMS, Rosa AL, de Oliveira PT. In vitro osteogenesis on a microstructured titanium surface with additional submicron-scale topography. Clin Oral Implants Res 2007;18:333-344.

Shekaran A, Garcia AJ. Nanoscale engineering of extracellular matrix-mimetic bioadhesive surfaces and implants for tissue engineering. Biochim Biophys Acta. 2010 May 8. [Epub ahead of print]. 
Siebers MC, ter Brugge PJ, Walboomers XF, Jansen JA. Integrins as linker proteins between osteoblasts and bone replacing materials. A critical review. Biomaterials 2005;26:137-146.

Smith LA, Ma PX. Nano-fibrous scaffolds for tissue engineering. Colloids Surf B Biointerfaces 2004;39:125-131.

Spiro RC, Liu LS, Heidaran MA, Thompson AY, Ng, CK, Pohl J., Poser JW. Inductive activity of recombinant human growth and differentiation factor-5. Biochemical Society Transactions 2000;28:362-368.

Stevens $\mathrm{MM}$, George $\mathrm{JH}$. Exploring and engineering the cell surface interface. Science 2005;310:1135-1138.

Tan J, Saltzman WM. Biomaterials with hierarchically defined micro- and nanoscale structure. Biomaterials 2004;25:3593-3601.

Variola F, Vetrone F, Richert L, Jedrzejowski P, Yi JH, Zalzal S, Clair S, Sarkissian A, Perepichka DF, Wuest JD, Rosei F, Nanci A. Improving biocompatibility of implantable metals by nanoscale modification of surfaces: an overview of strategies, fabrication methods, and challenges. Small 2009;5:996-1006.

Vetrone F, Variola F, Tambasco de Oliveira P, Zalzal SF, Yi JH, Sam J, BombonatoPrado KF, Sarkissian A, Perepichka DF, Wuest JD, Rosei F, Nanci A. Nanoscale oxidative patterning of metallic surfaces to modulate cell activity and fate. Nano Lett 2009;9:659-665.

Webb K, Hlady V, Tresco Pa. Relative importance of surface wettability and charged functional groups on NIH 3T3 fibroblast attachment, spreading, and cytoskeletal organization. J Biomed Mater Res 1998;41:422-430.

Wieland M, Textor M, Chehroudi B, Brunette DM. Synergistic interaction of topographic features in the production of bone-like nodules on $\mathrm{Ti}$ surfaces by rat osteoblasts. Biomaterials 2005;26:1119-1130.

Yi J-H, Bernard C, Variola F, Zalzal SF, Wuest JD, Rosei F, Nanci A. Characterization of a bioactive nanotextured surface created by controlled chemical oxidation of titanium. Surf Sci 2006;60:4613-4621.

Yoshimoto T, Yamamoto M, Kadomatsu H, Sakoda K, Yonamine Y, Izumi Y. Recombinant human growth/differentiation factor-5 (rhGDF-5) induced bone formation in murine calvariae. J Periodontal Res 2006;41:140-147.

Zinger O, Anselme K, Denzer A, Habersetzer P, Wieland M, Jeanfils J, Hardouin P, Landolt D. Time-dependent morphology and adhesion of osteoblastic cells on titanium model surfaces featuring scale-resolved topography. Biomaterials 2004;25:2695-2711. 


\section{RESUMO:}

Modificações bioquímicas de topografias complexas de $\mathrm{Ti}$ permitem o desenvolvimento de novas superfícies de implantes funcionalizadas com moléculas bioativas, visando a promover a osteogênese de contato e a osseointegração. $O$ objetivo do presente estudo foi avaliar o desenvolvimento do fenótipo osteogênico in vitro sobre diferentes nanotopografias de titânio (Ti) funcionalizadas com o fator de crescimento GDF-5. Células osteogênicas derivadas de calvária de ratos recémnascidos foram plaqueadas e cultivadas por até 14 dias sobre superfícies de discos de Ti: 1) Controle (usinada e polida); 2) 30' (com nanotopografia de nanoporos menores, obtida por condicionamento em solução de $\mathrm{H}_{2} \mathrm{SO}_{4} / \mathrm{H}_{2} \mathrm{O}_{2}$ por 30 min); 3) 30'+GDF-5 (nanotopografia de 30', pré-adsorvida com GDF-5 a 200 ng/mL); 4) 4h (com nanotopografia de nanoporos maiores, obtida por condicionamento em $\mathrm{H}_{2} \mathrm{SO}_{4} / \mathrm{H}_{2} \mathrm{O}_{2}$ por $4 \mathrm{~h}$ ); 5) 4h+GDF-5 (nanotopografia de $4 \mathrm{~h}$, pré-adsorvida com GDF-5 a $200 \mathrm{ng} / \mathrm{mL}$ ). A adsorção de GDF-5 foi realizada a $4^{\circ} \mathrm{C}$ por $12 \mathrm{~h}$ no dia anterior ao plaqueamento das células. Os resultados mostraram que não houve diferenças estatisticamente significantes entre os grupos para a viabilidade celular em 1, 3 e 7 dias. Em 3 dias, as células estavam aderidas e espraiadas sobre todas as superfícies e acúmulos extracelulares extensos de OPN foram encontrados apenas sobre superfícies com nanotopografia de 4 h e de 30'+GDF-5. A expressão de RNAm para RUNX2 e ALP foi maior em 7 dias se comparada a 10 dias, sendo os menores valores encontrados para o grupo 4h+GDF-5. A expressão de OPN aumentou de 7 para 10 dias, exceto para 30'+GDF-5, que se manteve inalterada. Enquanto que os níveis de RNAm para BSP aumentaram de 7 para 10 dias no Controle, redução 
significativa foi observada para os demais grupos, exceto para 30', em que se manteve constante. Culturas crescidas sobre nanotopografias funcionalizadas com GDF-5 exibiram os maiores valores de atividade de ALP em 10 dias e de áreas de matriz mineralizada/acúmulos de cálcio em 14 dias. Em conclusão, a funcionalização de nanotopografias de Ti com GDF-5 pode acelerar e/ou aumentar a expressão do fenótipo osteogênico in vitro. 


\section{SUMÁRIO}

LISTA DE ABREVIATURAS E SIGLAS ..........................................................

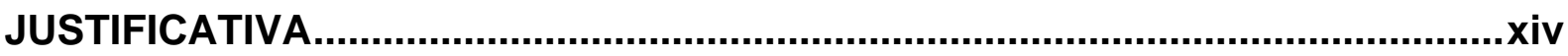

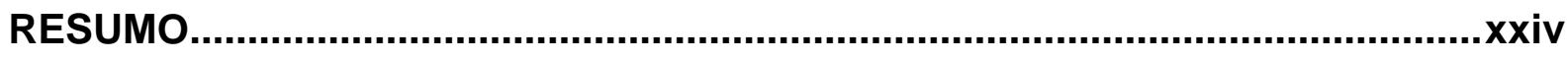

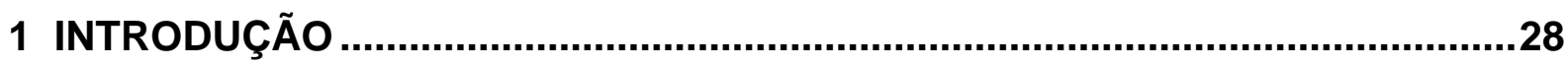

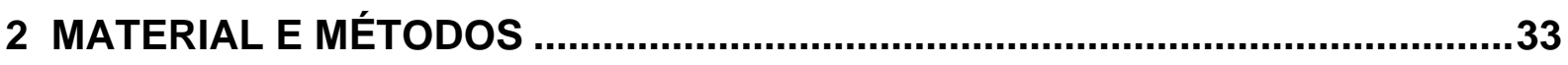

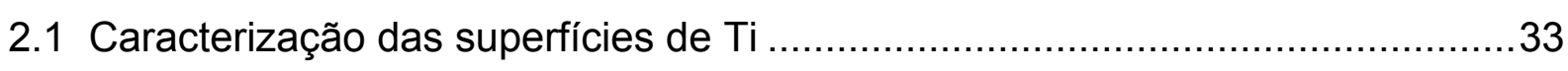

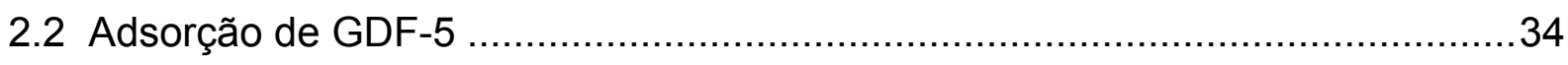

2.3 Isolamento celular e culturas de células osteogênicas........................................34

2.4 Morfologia celular e estágios de adesão e espraiamento celular ........................35

2.5 Determinação da viabilidade celular, da proporção de células no ciclo celular

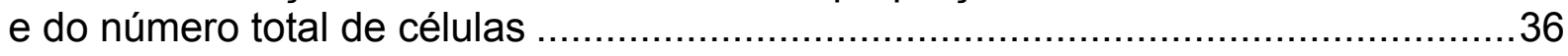

2.6 Imunolocalização de osteopontina (OPN), sialoproteína óssea (BSP) e do

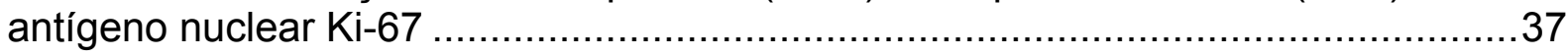

2.7 Análise do grau de diferenciação osteoblástica por reação em cadeia da

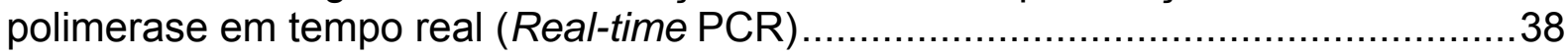

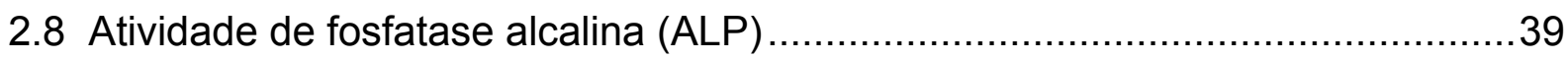

2.9 Detecção de acúmulos de cálcio (formação de matriz mineralizada).................40

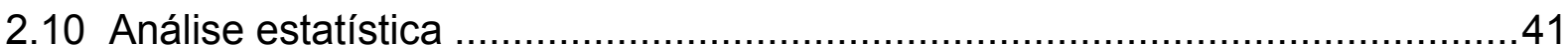

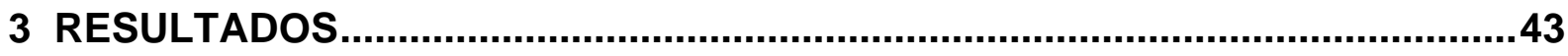

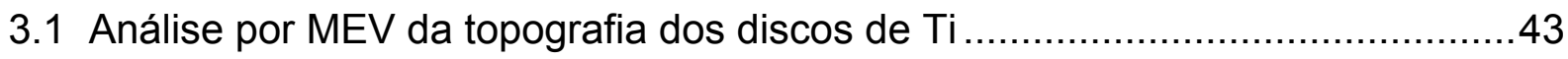

3.2 Estágios de adesão e espraiamento celular .................................................43

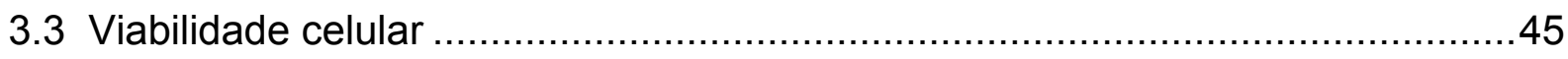

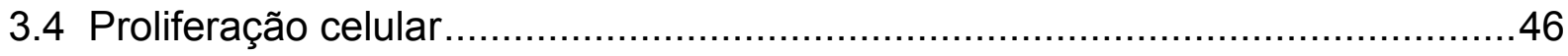

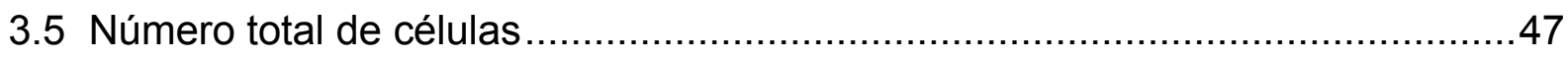

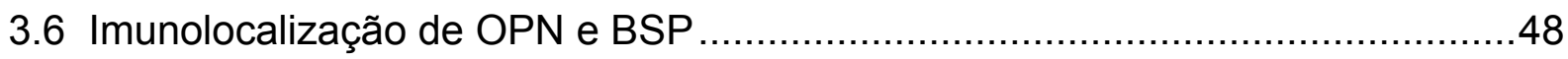

3.7 Análise do grau de diferenciação osteoblástica por Real time PCR ..................49

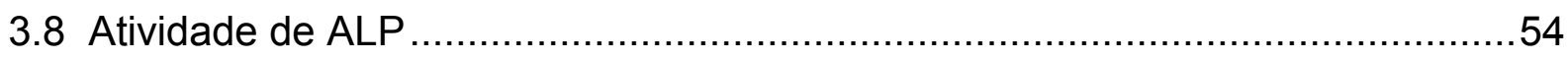

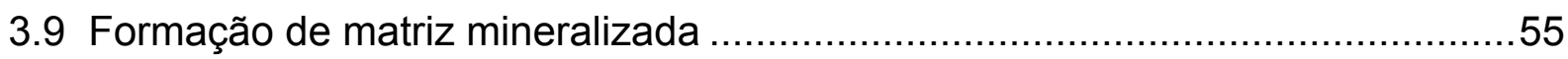

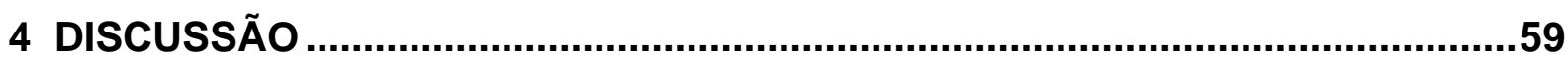

5 CONCLUSÃO

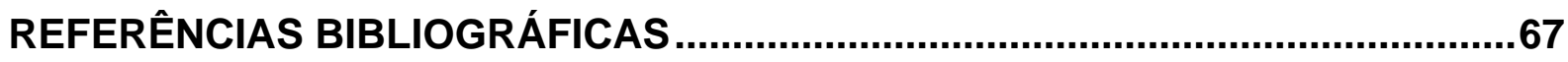




\section{INTRODUÇÃO:}

Em Implantologia, estudos experimentais e clínicos vêm demonstrando os benefícios do desenvolvimento de superfícies de implantes com microtopografias complexas e modificações de sua composição química para o processo de formação e remodelação óssea na região interfacial (DAVIES 1998; PARK et al. 2001; LOSSDORFER et al. 2004; MENDONÇA et al. 2008; SCHWARZ et al. 2009). Entretanto, novas estratégias para a modificação de características da superfície de implantes metálicos têm sido propostas com o objetivo de aumentar e/ou acelerar a atividade osteogênica em sítios de baixa densidade óssea e para casos de carga imediata (MOY et al. 2005; BORNSTEIN et al. 2009; BEUTNER et al. 2010), o que deverá representar a nova geração de implantes osseointegráveis. Entre essas estratégias destacam-se as modificações topográficas na nanoescala e as bioquímicas, com a disponibilização de moléculas bioativas (funcionalização de superfície), ou a combinação de ambas (MORRA et al. 2007; JUNKER et al. 2009; SHEKARAN \& GARCIA 2010; BEUTNER et al. 2010).

Com o advento da Nanotecnologia, desenvolvem-se diferentes métodos para a criação de nanotopografias visando ao controle das atividades celulares e da formação tecidual em contato com biomateriais (MENDONÇA et al. 2008; RICHERT et al. 2008; VARIOLA et al. 2009; VETRONE et al. 2009). Com efeito, aspectos nanotopográficos de superfície afetam seletivamente as funções de diferentes tipos celulares e estágios de diferenciação, com consequente impacto no desenvolvimento do fenótipo tecidual (LORD et al. 2010). Em relação à resposta de células do tecido ósseo e da medula óssea, com sua característica heterogeneidade 
fenotípica, superfícies metálicas nanomodificadas favorecem a expansão de células tronco e seu comprometimento com a diferenciação osteoblástica (VETRONE et al. 2009), com maior expressão dos marcadores RUNX2, ALP e BSP (MENDONÇA et al. 2009; MENDONÇA et al. 2010). Além disso, nanotopografias estimulam os processos de adesão (WEBSTER et al. 2001; WEBSTER et al. 2004; KHANG et al. 2008; PUCKETT et al. 2008; YANG et al. 2009), espraiamento (LE GUEHENNEC et al. 2008; VETRONE et al. 2009), proliferação (VETRONE et al. 2009; YANG et al. 2009) e função de osteoblastos (ELIAS et al. 2002; PRICE et al. 2003; DE OLIVEIRA \& NANCI 2004; DE OLIVEIRA et al. 2007; LE GUEHENNEC et al. 2008; YAO et al. 2008; YANG et al. 2009; VETRONE et al. 2009), enquanto que inibem o crescimento de fibroblastos (PRICE et al. 2004; RICHERT et al. 2008; VETRONE et al. 2009). Em estudo utilizando a técnica de PCR Array para genes associados à adesão e migração celulares, Vetrone et al. (2009) mostraram sobre-expressão da subunidade alfa 5 de integrina e de hialuronano em culturas osteogênicas crescidas sobre superfícies de Ti nanoestruturadas quimicamente. Todos esses aspectos contribuem para a maior produção de matriz mineralizada sobre nanotopografia de $\mathrm{Ti}$, como demonstrado em estudos in vitro (DE OLIVEIRA et al. 2007) e in vivo (MEIRELLES et al. 2007; MEIRELLES et al. 2008). Os efeitos da nanotopografia sobre as células podem ser diretos e/ou indiretos, respectivamente atribuídos aos aspectos geométricos na nanoescala e/ou ao impacto que essas nanomodificações exercem sobre o fenômeno de adsorção de proteínas, incluindo as plasmáticas e aquelas da matriz extracelular (MEC) (HOVGAARD et al. 2008; LORD et al. 2010; RICHERT et al. 2010).

A modificação bioquímica de superfícies de biomateriais visa à disponibilização de moléculas com efeitos estimuladores do processo de reparo 
tecidual (BEUTNER et al. 2010), entre as quais: 1) componentes principais da MEC do tecido ósseo, incluindo hidroxiapatita e colágeno tipo I (MORRA et al. 2003; RAMMELT et al. 2004; SCHARNWEBER et al. 2004; MORRA et al. 2006; VAN DEN DOLDER \& JANSEN 2007; MEIRELLES et al. 2008; YANG et al. 2010); 2) proteínas não-colágenas e fatores de crescimento da MEC óssea (O'TOOLE et al. 2004; WIKESJÖ et al. 2008; SCHOUTEN et al. 2009; SUSIN et al. 2010); 3) peptídios bioativos (REZANIA et al. 1999; ROESSLER et al. 2001; TOSATTI et al. 2004; GARCIA \& REYES 2005; LUTZ et al. 2010). Entre os diferentes métodos para a funcionalização de superfície, a simples adsorção de um desses componentes proteicos tem sido utilizada como estratégia vantajosa, de baixo custo e com efeitos biológicos relevantes (O'TOOLE et al. 2004; GARCIA \& REYES 2005; WIKESJÖ et al. 2008; SCHOUTEN et al. 2009). Como os fatores de crescimento estimulam diferentes funções celulares e, consequentemente, podem exercer efeitos positivos no processo de neoformação tecidual, sua disponibilização por simples adsorção poderia trazer benefícios ao processo de osseointegração. Nesse contexto, GDF-5, uma proteína da superfamília TGF- $\beta$ que desempenha papel fundamental no desenvolvimento dos esqueletos cartilaginoso e ósseo (FRANCIS-WEST et al. 1999; KUNIYASU et al. 2003; YOSHIMOTO et al. 2006), poderia representar uma opção interessante para a funcionalização de implantes metálicos. Com efeito, o mecanismo de ação do GDF-5 assemelha-se ao de proteínas morfogenéticas ósseas (BMPs; SPIRO et al. 2000), induzindo a formação ectópica de tecido ósseo (KUNIYASU et al. 2003; YOSHIMOTO et al. 2006). In vitro, o GDF-5 estimula a migração e proliferação celular, bem como a produção de MEC mineralizada (NAKAMURA et al. 2003; YOSHIMOTO et al. 2006). 
Considerando que aspectos topográficos na nanoescala da superfície de biomateriais afetam a adsorção de proteínas, o objetivo do presente trabalho foi avaliar os efeitos da funcionalização de nanotopografias de Ti por simples adsorção de GDF-5 sobre o desenvolvimento do fenótipo osteogênico in vitro. 


\section{MATERIAL E MÉTODOS:}

\subsection{Caracterização das superfícies de Ti:}

Discos de titânio comercialmente puro, grau 2, de $13 \mathrm{~mm}$ de diâmetro por 2 mm de altura (Realum, São Paulo, SP, Brasil), usinados, foram polidos com lixas de carbeto de silício de grana 320 e 600, lavados em ultra-som, tolueno, e submetidos a condicionamento em solução de $\mathrm{H}_{2} \mathrm{SO}_{4}$ a $10 \mathrm{~N}$ e $\mathrm{H}_{2} \mathrm{O}_{2}$ a $30 \%$ por 30 min (RICHERT et al. 2008; VARIOLA et al. 2008) e 4 horas (YI et al. 2006; DE OLIVEIRA et al. 2007; RICHERT et al. 2008; VARIOLA et al. 2008) à temperatura ambiente (T.A.), sob agitação constante. Os discos foram, em seguida, lavados em água destilada, autoclavados e secos ao ar. Discos controles foram preparados semelhantemente, com exceção à etapa de condicionamento com solução de $\mathrm{H}_{2} \mathrm{SO}_{4}$ e $\mathrm{H}_{2} \mathrm{O}_{2}$, não realizada.

Os grupos experimentais constituíram-se, portanto, de 5 superfícies distintas de Ti: 1) Controle - discos de Ti usinados e polidos; 2) 30' - Nanotopografia de Ti com nanoporos menores - discos de Ti usinados e polidos, submetidos a condicionamento em solução de $\mathrm{H}_{2} \mathrm{SO}_{4}$ a $10 \mathrm{~N}$ e $\mathrm{H}_{2} \mathrm{O}_{2}$ a $30 \%$ por 30 min; 3) 30'+GDF-5 - Nanotopografia de Ti com nanoporos menores, com GDF-5 adsorvido - superfícies de Ti nanomodificadas (30 min), previamente autoclavadas, incubadas com solução de GDF-5 a 200 ng/mL (recombinant human GDF-5, Peprotech, México) overnight a $4^{\circ} \mathrm{C}$; 4) $4 \mathrm{~h}$ - Nanotopografia de Ti com nanoporos maiores discos de Ti usinados e polidos, submetidos a condicionamento em solução de $\mathrm{H}_{2} \mathrm{SO}_{4}$ a $10 \mathrm{~N}$ e $\mathrm{H}_{2} \mathrm{O}_{2}$ a $30 \%$ por $4 \mathrm{~h}$; 5) 4h+GDF-5 - Nanotopografia de Ti com nanoporos maiores, com GDF-5 adsorvido - superfícies de Ti nanomodificadas (4 h), 
previamente autoclavadas, incubadas com solução de GDF-5 a 200 ng/mL (recombinant human GDF-5, Peprotech) overnight a $4{ }^{\circ} \mathrm{C}$.

Para a caracterização qualitativa de aspectos topográficos na nanoescala, discos de $\mathrm{Ti}$ controle e com nanotopografias, selecionados aleatoriamente, foram examinados em microscópio eletrônico de varredura de emissão de campo JEOL JSM-7400F (JEOL, Tokyo, Japão) operado a 1-2 kV.

\subsection{Adsorção de GDF-5:}

No dia anterior ao plaqueamento das células, superfícies de $\mathrm{Ti}$ nanomodificadas, previamente autoclavadas, foram incubadas overnight a $4{ }^{\circ} \mathrm{C}$ com solução de GDF-5 a 200 ng/mL (recombinant human GDF-5, Peprotech, México) em placas de poliestireno de 24 poços. Em seguida, os discos de Ti foram lavados três vezes com PBS a $37^{\circ} \mathrm{C}$ e deixados a secar à T.A., previamente ao plaqueamento das células.

\subsection{Isolamento celular e culturas de células osteogênicas:}

As células foram isoladas por digestão enzimática seqüencial, com solução de tripsina e colagenase, de fragmentos de calvárias de ratos Wistar recém-nascidos, com 2-4 dias (NANCl et al. 1996; IRIE et al. 1998; DE OLIVEIRA et al. 2003; DE OLIVEIRA \& NANCI 2004; DE OLIVEIRA et al. 2007; SCHWARTZ FO et al. 2007). Todos os procedimentos com animais estavam de acordo com os Princípios Éticos na Experimentação Animal adotados pela Comissão de Ética no Uso de Animais (CEUA) do Campus de Ribeirão Preto da USP (Protocolo $n^{\circ}$ 08.1.836.53.1). As células foram plaqueadas sobre os discos de Ti contidos em placas de 24 poços, na densidade de $2 \times 10^{4}$ células/poço, e foram cultivadas por períodos de até 14 dias em 
Meio Essencial Mínimo, modificação $\alpha$, com L-glutamina ( $\alpha-M E M ;$ Invitrogen, Carlsbad, EUA), suplementado com $10 \%$ de soro fetal bovino (Invitrogen), $7 \mathrm{mM}$ de $\beta$-glicerofosfato (Sigma, St Louis, EUA), $50 \mu \mathrm{g} / \mathrm{mL}$ de gentamicina (Invitrogen), 5 $\mu \mathrm{g} / \mathrm{mL}$ de ácido ascórbico (Sigma) a $37^{\circ} \mathrm{C}$ em uma atmosfera úmida contendo $5 \%$ de $\mathrm{CO}_{2}$. O meio de cultura foi trocado a cada 2-3 dias e a progressão da cultura foi avaliada por microscopia de fase em culturas crescidas sobre poliestireno.

\subsection{Morfologia celular e estágios de adesão e espraiamento celular:}

A adesão e espraiamento celular foram avaliados por fluorescência direta utilizando faloidina conjugada com Alexa Fluor 488 (Molecular Probes, Eugene, EUA), para marcação do citoesqueleto de actina, e 4',6-diamidino-2-phenylindole, dihydrochloride (DAPI, Molecular Probes), para marcação do DNA nuclear (descrição no item 2.6). Determinaram-se, em $4 \mathrm{~h}$, as proporções de células nos estágios 1 (esféricas), 2 (esféricas com filopódios), 3 (com filopódios e lamelipódios) e 4 (espraiadas) (Figura 1; RAJARAMAN et al. 1974), avaliando-se pelo menos 100 células aderidas, em campos microscópicos selecionados aleatoriamente, em 40X.

Estágios de adesão e espraiamento

1

2

3

4
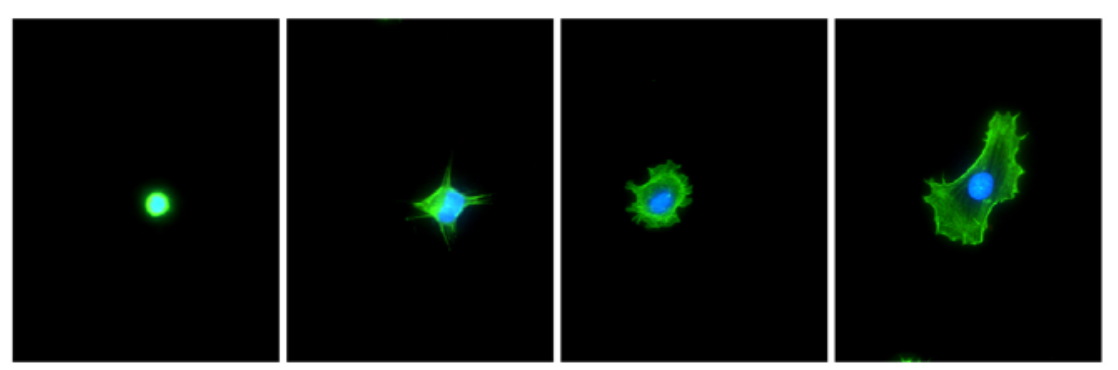

Figura 1. Aspectos morfológicos de células nos diferentes estágios de adesão e espraiamento in vitro. Epifluorescência para visualização do citoesqueleto de actina (verde) e núcleos (azul) de células osteogênicas cultivadas por $4 \mathrm{~h}$ sobre Ti com nanotopografia (40X). 


\subsection{Determinação da viabilidade celular, da proporção de células no ciclo celular e do número total de células:}

Em 1, 3 e 7 dias, a viabilidade celular foi avaliada nos diferentes grupos pelo ensaio colorimétrico MTT \{brometo de [3-(4,5-dimetiltiazol-2-il)-2,5-difeniltetrazolio]\} (Sigma), um sal que é reduzido por proteinases mitocondriais, ativas apenas em células viáveis (MOSMANN 1983). Alíquotas de MTT a 5 mg/mL em solução tampão salina de fosfato (Phosphate buffered saline - PBS; Gibco, Invitrogen) foram preparadas, procedendo-se em seguida à incubação das culturas primárias com esta solução a $10 \%$ em meio de cultura, por 4 horas a $37^{\circ} \mathrm{C}$, em atmosfera umidificada contendo $5 \%$ de $\mathrm{CO}_{2}$ e $95 \%$ de ar atmosférico. Após esse período, as culturas foram lavadas com $1 \mathrm{~mL}$ de PBS aquecido. Em seguida, foi adicionado 1 $\mathrm{mL}$ de solução de isopropanol ácido (100 mL de isopropanol e $134 \mu \mathrm{L}$ de $\mathrm{HCl}$ ) em cada poço sob agitação por 5 min, para a solubilização completa do precipitado formado. Alíquotas de $200 \mu \mathrm{L}$ foram retiradas dos poços e transferidas para placa de 96 poços para medida colorimétrica em espectrofotômetro ( $\mu$ Quanti, BioTek Instruments, Inc., Winooski, EUA), utilizando comprimento de onda de $570 \mathrm{~nm}$.

Em 3 dias, foi determinada a proporção de células no ciclo celular por imunomarcação ao antígeno nuclear Ki-67, expresso apenas por células durante o ciclo celular e não por células em G0 (SCHOLZEN \& GERDES 2000). Foram avaliados, por epifluorescência, 5 discos de cada grupo experimental, em objetiva de 40X, determinando-se a proporção de células Ki-67 positivas de um total de células aderidas e espraiadas não inferior a 100 (3 a 5 campos microscópicos), quantificadas pela marcação do DNA nuclear por DAPI. Os métodos de imunofluorescência indireta, para a localização de Ki-67, e fluorescência direta, para marcação do DNA nuclear por DAPI, estão descritos no item 2.6. 
Para quantificar o número total de células em 7 dias, células osteogênicas foram enzimaticamente destacadas das superfícies de Ti por ação de solução contendo $1,5 \mathrm{~mL}$ de EDTA a $1 \mathrm{mM}, 1,3 \mathrm{mg} / \mathrm{mL}$ de colagenase e tripsina a $0,25 \%$ (Gibco, Invitrogen). O número de células viáveis e não viáveis foi contado por meio de hemocitômetro, após a marcação com azul de Tripan (Sigma). O resultado foi expresso como o número total de células por poço.

\subsection{Imunolocalização de osteopontina (OPN), sialoproteína óssea (BSP) e do antígeno nuclear Ki-67:}

Em 3 e7 dias, as células foram fixadas em paraformaldeído a 4\% em tampão fosfato a $0,1 \mathrm{M}, \mathrm{pH}$ 7,2 (PB), por 10 min à temperatura ambiente (TA). Em seguida, as células foram processadas rotineiramente para imunofluorescência indireta (DE OLIVEIRA \& NANCI 2004; DE OLIVEIRA et al. 2007; SCHWARTZ FO et al. 2007). As células foram permeabilizadas com solução de Triton X-100 a 0,5\% (Acros Organics, Geel, EUA) em PB por 10 min, seguida de bloqueio com leite desnatado a 5\% em PB por 30 min. Utilizaram-se anticorpos primários monoclonais para BSP (1:200, WVID1-9C5, Developmental Studies Hybridoma Bank - DSHB, lowa City, EUA) e OPN (1:800, MPIIIB10-1, DSHB), e policlonal para Ki-67 (1:70, Diagnostic Biosystems, Pleasanton, EUA), seguidos de anticorpos secundários conjugados com fluoróforo Alexa Fluor 594 (fluorescência vermelha; 1:200, Molecular Probes) em mesma solução de faloidina conjugada com Alexa Fluor 488 (fluorescência verde; 1:200, Molecular Probes), para visualização do citoesqueleto de actina. Todas as incubações dos anticorpos foram feitas em atmosfera úmida por 60 min à T.A. Entre cada incubação, as amostras foram lavadas três vezes (5 min cada) em PB. Antes da montagem para observação microscópica, as amostras foram lavadas 
rapidamente com água destilada e os núcleos celulares, marcados com DAPI (Molecular Probes) a $300 \mathrm{nM}$ por 5 min. Os discos foram montados em lâminas de vidros, e em seguida, após montagem de lamínula de vidro Fisherbrand $12 \mathrm{~mm}$ (Fisher Scientific, Pittsburgh, EUA) com meio de montagem anti-fade (Vectashield, Vector Labs, Burlingame, EUA) sobre as superfícies contendo células, as amostras foram examinadas em microscópio de fluorescência Leica DMLB (Leica, Bensheim, Alemanha) acoplado a uma câmera digital. As imagens adquiridas foram processadas com o programa Adobe Photoshop.

\subsection{Análise do grau de diferenciação osteoblástica por reação em cadeia da polimerase em tempo real (Real-time PCR):}

A expressão de marcadores do fenótipo osteoblástico foi avaliada por Realtime PCR, quantificando-se os seguintes genes: RUNX2, ALP, BSP e OPN. Como controle, foi avaliada a expressão do gene constitutivo GAPDH.

Nos tempos de 7 e 10 dias, foi realizada a extração do RNA total através do kit SV Total RNA Isolation System (Promega, Madison, EUA), de acordo com especificações do fabricante. Em seguida, o RNA total foi quantificado em diferentes comprimentos de onda (260, 280, 230 e 320 nm) no aparelho GeneQuant 1300 (GE Healthcare, Cardiff, Reino Unido).

Após extração do RNA total, o cDNA foi sintetizado a partir de $1 \mu \mathrm{g}$ de RNA por reação de transcrição reversa utilizando o Kit High Capacity cDNA Reverse Transcription (Applied Biosystems, Foster City, EUA), de acordo com as instruções do fabricante. Brevemente, foram adicionados ao RNA: $2 \mu \mathrm{L}$ de (10X) RT buffer, 0,8 $\mu \mathrm{L}$ de $(25 \mathrm{X})$ dNTP mix (100 mM), $2 \mu \mathrm{L}$ (10X) RT Random Primers, $1 \mu \mathrm{L}$ de MultiScribe Reverse Transcriptase, $1 \mu \mathrm{L}$ de RNase Inhibitor e 3,2 $\mu \mathrm{L}$ de água DEPC, 
para um volume final de $20 \mu \mathrm{L} /$ reação. Em seguida, a amostra foi incubada a $25^{\circ} \mathrm{C}$ por $10 \mathrm{~min}, 37^{\circ} \mathrm{C}$ por $120 \mathrm{~min}, 85^{\circ} \mathrm{C}$ por $5 \mathrm{~min}$, seguido pelo resfriamento a $4^{\circ} \mathrm{C}$. Ao final da reação a amostra foi mantida refrigerada e o cDNA foi estocado em freezer a $-20^{\circ} \mathrm{C}$.

Para as reações de Real-time PCR, foram utilizadas sondas $\operatorname{TaqMan}^{\circledR}$ (Applied Biosystems) em aparelho CFX96 (Bio-Rad, Hercules, EUA), com volume final de $10 \mu \mathrm{L}$ por reação. Para cada reação, foram adicionados $5 \mu \mathrm{L}$ de TaqMan Universal PCR Master Mix-No AmpErase UNG (2X), 0,5 $\mu \mathrm{L}$ das sondas TaqMan para os genes de interesse (20X TaqMan Gene Expression Assay Mix) e 11,25 ng de cDNA. As reações consistiram em 2 min a $50{ }^{\circ} \mathrm{C}, 10$ min a $95^{\circ} \mathrm{C}$, e quarenta ciclos de $15 \mathrm{~s}$ a $95^{\circ} \mathrm{C}$ e $1 \mathrm{~min}$ a $60^{\circ} \mathrm{C}$. Os resultados foram analisados com base no valor de Ct (cicle threshold - ou ciclo limiar) e todas as amostras foram submetidas a reações para a detecção de RNA mensageiro para o gene de expressão constitutiva GAPDH e uma amostra negativa (água) foi submetida à reação com cada sonda TaqMan utilizada. A normalização e quantificação relativa da expressão gênica foram realizadas pelo método de $2^{-\triangle \Delta C T}$ (LIVAK \& SCHMITTGEN, 2001). Usando o método de $2^{-\Delta \Delta C T}$, os dados foram representados como diferença (em vezes) na expressão gênica normalizada pelo gene constitutivo. Atribuiu-se valor 1 para cada marcador em culturas sobre a superfície usinada em 7 dias, permitindo, assim, comparações entre grupos e tempos experimentais.

\subsection{Atividade de fosfatase alcalina (ALP):}

A atividade de ALP foi avaliada em 7 e 10 dias, através da liberação de timolftaleína por hidrólise do substrato de timolftaleína monofosfato, utilizando kit comercial de acordo com as instruções do fabricante (Labtest Diagnóstica, Belo 
Horizonte, Brasil). Primeiramente, $50 \mu \mathrm{L}$ de timolftaleína monofosfato foram misturados com $0,5 \mathrm{~mL}$ de tampão dietanolamina a $0,3 \mathrm{M}, \mathrm{pH} 10,1$, e deixados por 2 $\min$ a $37^{\circ} \mathrm{C}$. À solução foi, então, acrescentada alíquota de $50 \mu \mathrm{L}$ obtida de cada poço, permanecendo por 10 min a $37^{\circ} \mathrm{C}$. Para obter a coloração, foram adicionados $2 \mathrm{~mL}$ de $\mathrm{Na}_{2} \mathrm{CO}_{3}$ a 0,09 M e NaOH a 0,25 M. Após 30 min, a absorbância foi medida em espectrofotômetro (CE3021; Cecil, Cambridge, Reino Unido) utilizando comprimento de onda de $590 \mathrm{~nm}$ e a atividade de ALP, medida a partir da curva padrão, usando a timolftaleína em uma escala de 0,012 a 0,4 $\mu$ mol de timolftaleína/h/mL. Os dados foram normalizados pelo conteúdo de proteína total, que foi determinado pelo método de Lowry modificado (LOWRY et al. 1951).

\subsection{Detecção de acúmulos de cálcio (formação de matriz mineralizada):}

Em 14 dias, culturas primárias crescidas sobre os discos de Ti foram lavadas em solução de Hanks, fixadas em álcool etílico a $70 \%$ a $4{ }^{\circ} \mathrm{C}$ por 60 min e lavadas em PBS e água bidestilada. Em seguida, foram coradas com ARS a 2\%, pH 4,2, à T.A. por 15 min, lavadas com PBS e água bidestilada, e deixadas a secar à T.A.

Morfologicamente, as proporções de áreas marcadas com ARS foram determinadas pelo programa Image Tool (University of Texas Health Science Center, San Antonio, TX, EUA), a partir da transformação binária de imagens macroscópicas das culturas obtidas digitalmente com câmera de alta resolução (Canon EOS Digital Rebel, 6.3 MP, com lente macro EF100 f/2.8).

Bioquimicamente, acúmulos de cálcio foram quantificados pelo método de extração de ARS (GREGORY et al. 2004). Em cada poço contendo os discos de Ti corados com ARS, foram adicionados $280 \mu \mathrm{l}$ de ácido acético a 10\%, mantendo-se a placa sob agitação suave por 30 min. A camada de células foi, então, removida com 
um raspador de células e a solução, transferida para tubos de 1,5 $\mathrm{ml}$ e agitada em vortex por $30 \mathrm{~s}$. Em seguida, as amostras foram aquecidas a $85^{\circ} \mathrm{C}$ por $10 \mathrm{~min}$, resfriadas em gelo por 5 min e centrifugadas a $13.000 \mathrm{~g}$ por $20 \mathrm{~min}$. De cada grupo experimental foram transferidos $100 \mu$ de sobrenadante para placa de 96 poços e adicionados $40 \mu \mathrm{l}$ de hidróxido de amônio a 10\% em cada poço. As amostras foram lidas em espectrofotômetro ( $\mu$ Quanti, BioTek Instruments), utilizando comprimento de onda de $405 \mathrm{~nm}$. A curva padrão foi realizada com dissoluções sucessivas de ARS de 0,5 a 3 mM em acetato de amônio (ácido acético a 10\% e hidróxido de amônio a 5 M).

\subsection{Análise estatística:}

Foi utilizado o teste paramétrico ANOVA, para dados independentes, a um ou dois fatores de variação, seguido do teste de Tukey, para comparações múltiplas, quando aplicável. O nível de significância foi de $5 \%$. Os resultados são representativos de experimentos realizados com pelo menos duas culturas primárias distintas. 


\section{RESULTADOS:}

\subsection{Análise por MEV da topografia dos discos de Ti:}

A análise qualitativa da topografia dos discos de Ti revelou que as superfícies do grupo Controle eram relativamente lisas, caracterizadas por aspectos topográficos típicos de superfícies usinadas e polidas, com eventuais sulcos superficiais nas escalas micro e submicrométrica, de distribuição aleatória (Figura 2A). Os discos de $\mathrm{Ti}$ submetidos ao tratamento químico com $\mathrm{H}_{2} \mathrm{SO}_{4} / \mathrm{H}_{2} \mathrm{O}_{2}$ apresentavam superfície caracterizada por rede de nanocavidades, de dimensões relativamente maiores para os grupos $4 \mathrm{~h}$ e $4 \mathrm{~h}+\mathrm{GDF}-5$ em comparação aos de 30' e 30'+GDF-5 (Figura 2,B-E). A adsorção de GDF-5 aparentemente não alterou os aspectos nanotopográficos das superfícies de Ti.
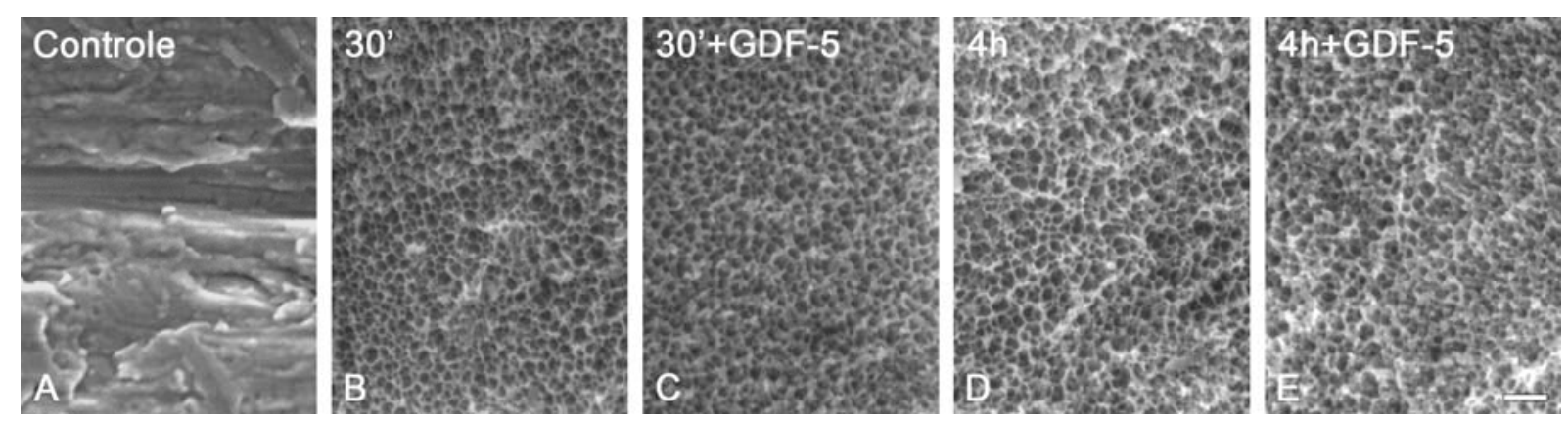

Figura 2. Microscopia eletrônica de varredura das diferentes superfícies de $\mathrm{Ti}$ (A-E). As nanotopografias (B-E) foram obtidas por condicionamento com solução de $\mathrm{H}_{2} \mathrm{SO}_{4} / \mathrm{H}_{2} \mathrm{O}_{2}$ por 30 min $(B, C)$ e $4 \mathrm{~h}(\mathrm{D}, \mathrm{E})$. Note-se rede de nanocavidades para os grupos 30' e 30'+GDF-5 (nanocavidades menores), $4 \mathrm{~h}$ e $4 \mathrm{~h}+\mathrm{GDF}-5$ (nanocavidades maiores). Barra $=100 \mathrm{~nm}$.

\subsection{Estágios de adesão e espraiamento celular:}

Culturas crescidas sobre as superfícies nanomodificadas com adsorção de GDF-5 revelaram uma proporção significativamente menor de células nos estágios 3 e 4 (células espraiadas) quando comparadas com o grupo Controle, 30' e 4h (ANOVA, p<0,05; Figuras 3, 4 e 5; Tabelas 1 e 10). 

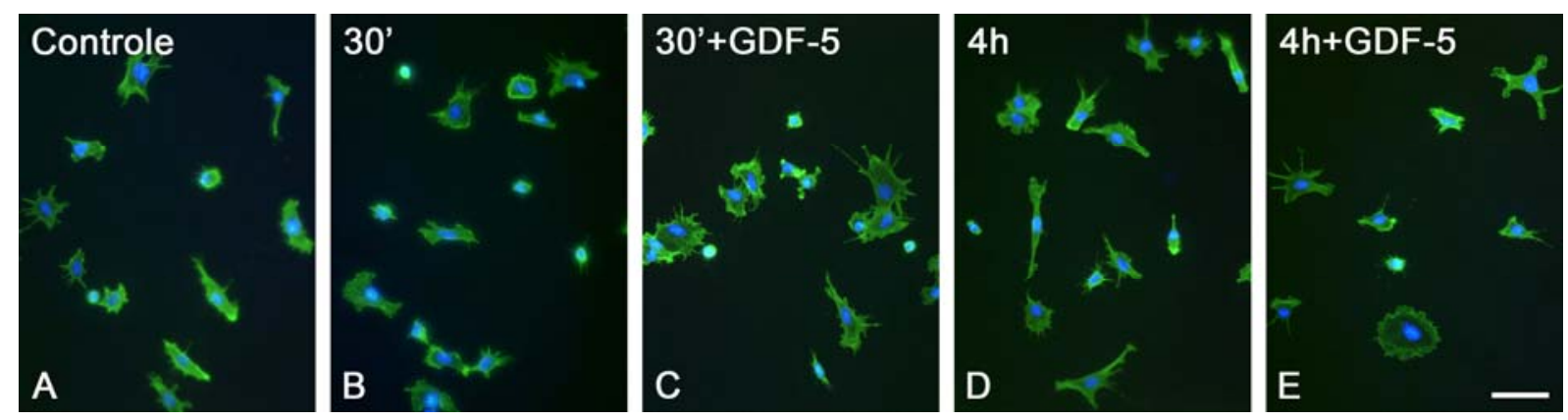

Figura 3.. Epifluorescência de culturas osteogênicas crescidas sobre as superfícies de Ti por $4 \mathrm{~h}$. Marcação em verde indica citoesqueleto de actina e em azul, núcleos celulares. Os grupos 30'+GDF5 (C) e 4h+GDF-5 (E) exibiram menor espraiamento celular. Barra $=50 \mu \mathrm{m}$.

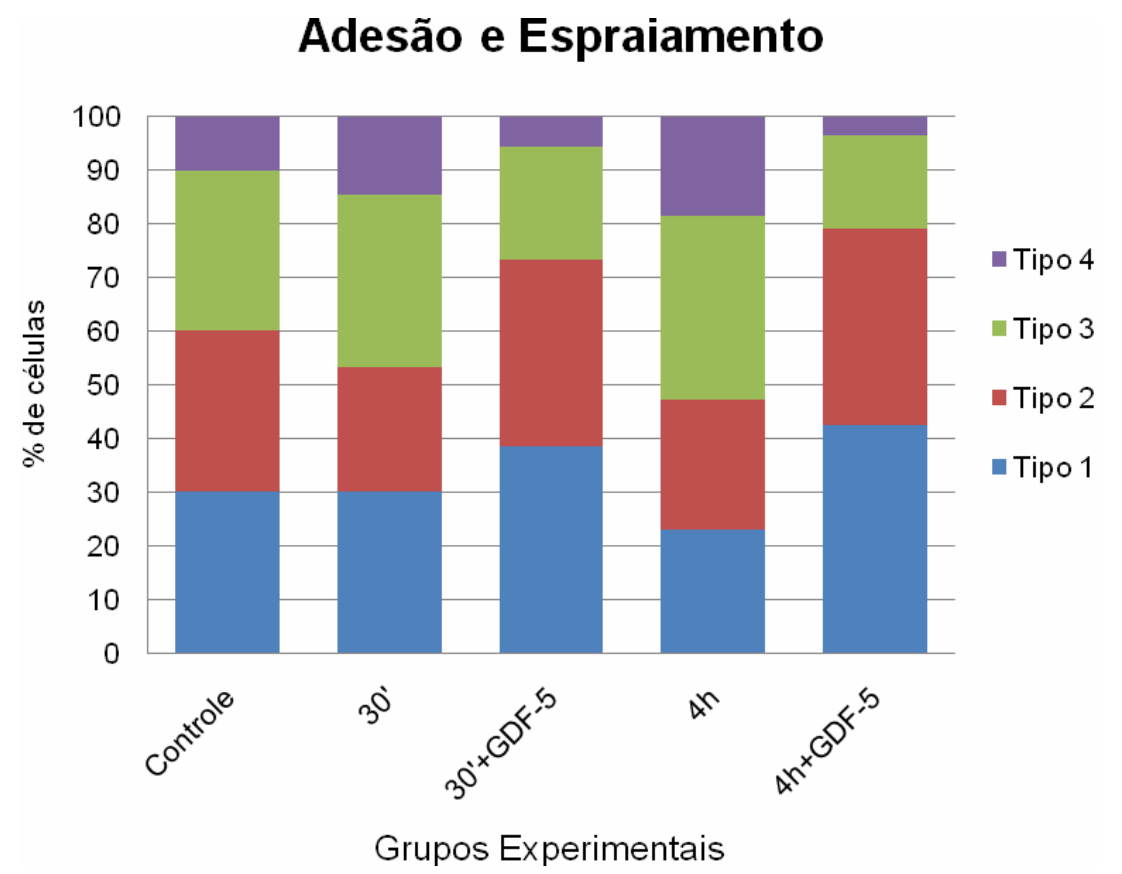

Figura 4. Estágios de adesão e espraiamento celulares (\% de células nos estágios 1, 2, 3 e 4) de culturas osteogênicas crescidas sobre as diferentes superfícies de $\mathrm{Ti}$ em $4 \mathrm{~h}$. Maiores proporções de células menos espraiadas (estágios 1 e 2) são observadas para as culturas crescidas sobre nanotopografias de Ti com GDF-5. 


\section{Adesão e Espraiamento}

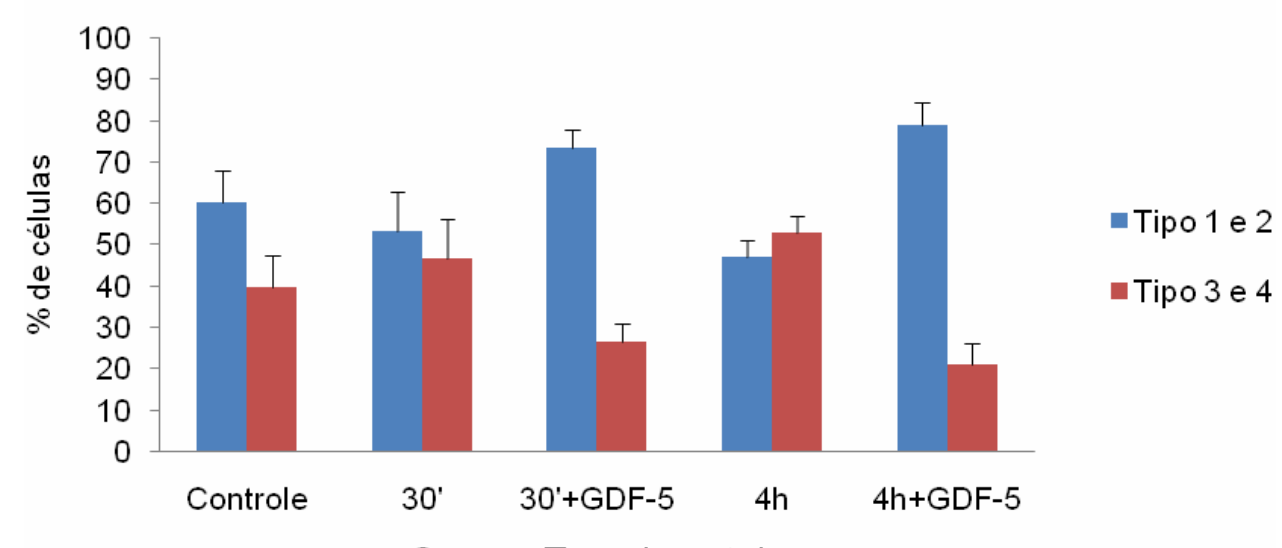

Grupos Experimentais

Figura 5. Proporção relativa de células nos estágios 1 e 2 (arredondadas) e 3 e 4 (espraiadas) em culturas osteogênicas sobre diferentes superfícies de Ti em $4 \mathrm{~h}$. Observam-se menores proporções de células nos estágios 3 e 4 sobre as superfícies dos grupos 30'+GDF-5 e 4h+GDF-5.

Tabela 1 - Análise de variância a dois fatores de variação (pós-teste de Tukey) referente aos estágios de adesão e espraiamento celular em $4 \mathrm{~h}$ em culturas osteogênicas sobre as diferentes superfícies de Ti. Os grupos e os estágios de adesão e espraiamento estão indicados por números, de 1 a 10

\begin{tabular}{|c|l|}
\hline 1 & Controle - Estágio 1 e 2 \\
\hline 2 & $30^{\prime}-$ Estágio 1 e 2 \\
\hline 3 & $30^{\prime}+$ GDF-5 - Estágio 1 e 2 \\
\hline 4 & $4 \mathrm{~h}$ - Estágio 1 e 2 \\
\hline 5 & $4 \mathrm{~h}+$ GDF-5 - Estágio 1 e 2 \\
\hline 6 & Controle - Estágio 3 e 4 \\
\hline 7 & $30^{\prime}$ - Estágio 3 e 4 \\
\hline 8 & $30^{\prime}+$ GDF-5 - Estágio 3 e 4 \\
\hline 9 & $4 \mathrm{~h}$ - Estágio 3 e 4 \\
\hline 10 & $4 \mathrm{~h}+$ GDF-5 - Estágio 3 e 4 \\
\hline
\end{tabular}

\begin{tabular}{|c|c|c|c|c|c|c|c|c|c|c|}
\hline & 1 & 2 & 3 & 4 & 5 & 6 & 7 & 8 & 9 & 10 \\
\hline 1 & & & & & ${ }^{*}$ & & & & & \\
\hline 2 & & & & ${ }^{*}$ & ${ }^{*}$ & & & & & \\
\hline 3 & & & & & ${ }^{*}$ & & & & & \\
\hline 4 & & & & & & & & & & \\
\hline 5 & & & & & & & & & & \\
\hline 6 & ${ }^{*}$ & & ${ }^{*}$ & & ${ }^{*}$ & & & & & \\
\hline 7 & & & ${ }^{*}$ & & ${ }^{*}$ & & & & & \\
\hline 8 & ${ }^{*}$ & ${ }^{*}$ & ${ }^{*}$ & ${ }^{*}$ & ${ }^{*}$ & ${ }^{*}$ & ${ }^{*}$ & & ${ }^{*}$ & \\
\hline 9 & & & ${ }^{*}$ & & ${ }^{*}$ & & & & & \\
\hline 10 & ${ }^{*}$ & ${ }^{*}$ & ${ }^{*}$ & ${ }^{*}$ & ${ }^{*}$ & ${ }^{*}$ & ${ }^{*}$ & & ${ }^{*}$ & \\
\hline \multicolumn{70}{|c|}{${ }^{*} \mathbf{p}<0,05$} & & & \\
\hline
\end{tabular}

\subsection{Viabilidade celular:}

Não se observaram diferenças estatisticamente significantes para os valores de MTT entre os grupos experimentais em 1, 3 e 7 dias. A viabilidade celular foi progressivamente maior do $1^{\circ}$ ao $7^{\circ}$ dia para a maioria dos grupos, com exceção para 30'+GDF-5, de 1 para 3 dias (Figura 6 e Tabela 10). 


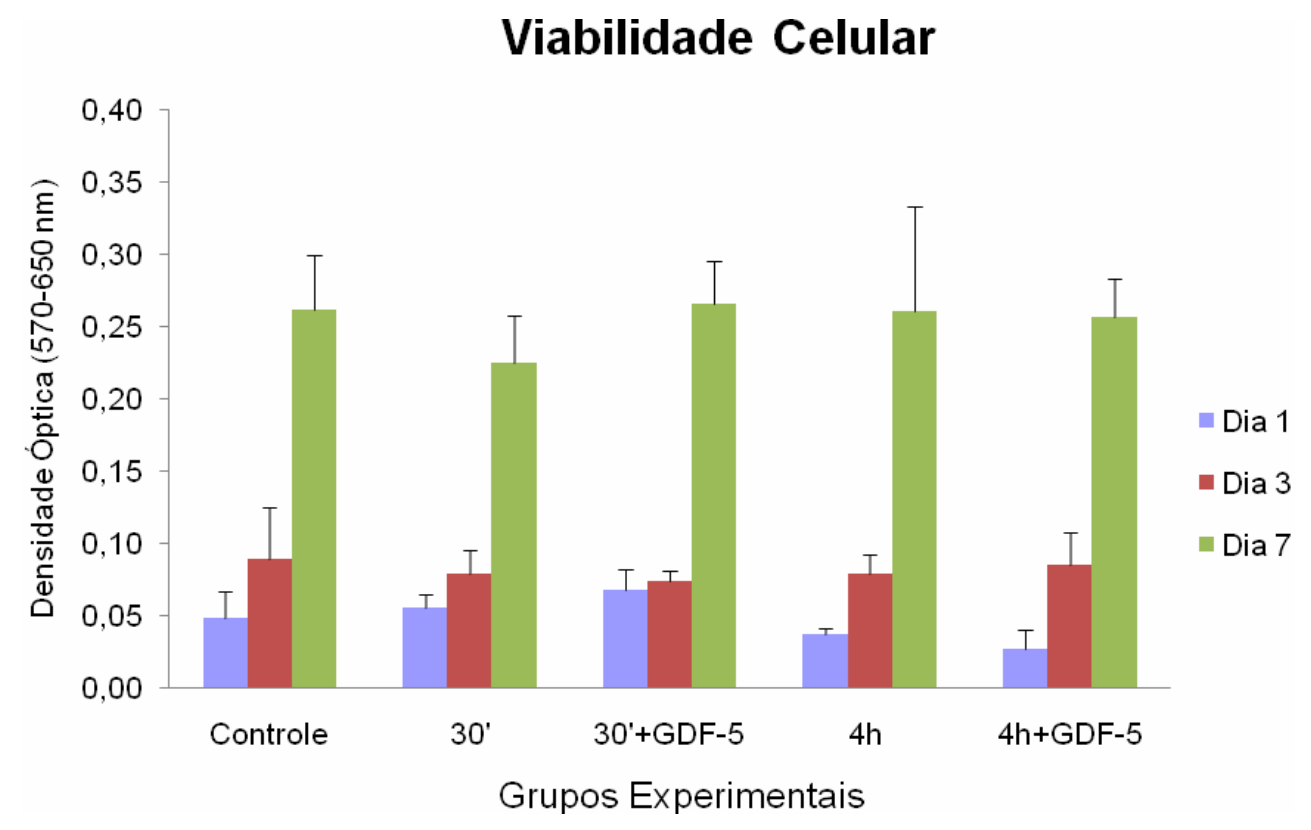

Figura 6. Viabilidade celular em 1, 3 e 7 dias, representada por valores de densidade óptica obtidos por leitura em espectrofotômetro, por ensaio de MTT. Notem-se valores progressivamente maiores em função do tempo durante a fase proliferativa das culturas primárias.

\subsection{Proliferação celular:}

Em 3 dias, as proporções de células Ki-67 positivas não se alteraram nas culturas osteogênicas crescidas sobre as diferentes superfícies de Ti (Figuras 7 e 8; Tabela 10).

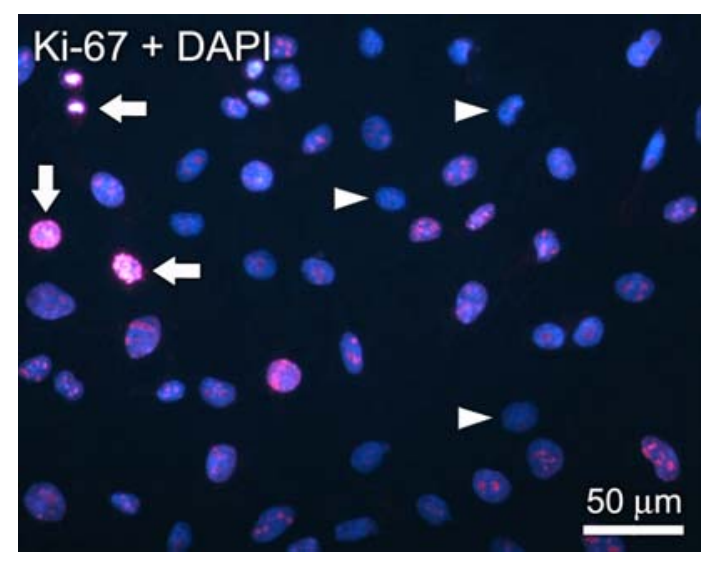

Figura 7. Epifluorescência de cultura osteogênica crescida sobre $\mathrm{Ti}$ com nanotopografia (4h) e GDF-5, em 3 dias, para a detecção de células proliferativas (Ki-67 positivas, fluorescência nuclear vermelha, setas). Células em G0 (cabeças de seta) são positivas apenas para DAPI (fluorescência nuclear azul). 


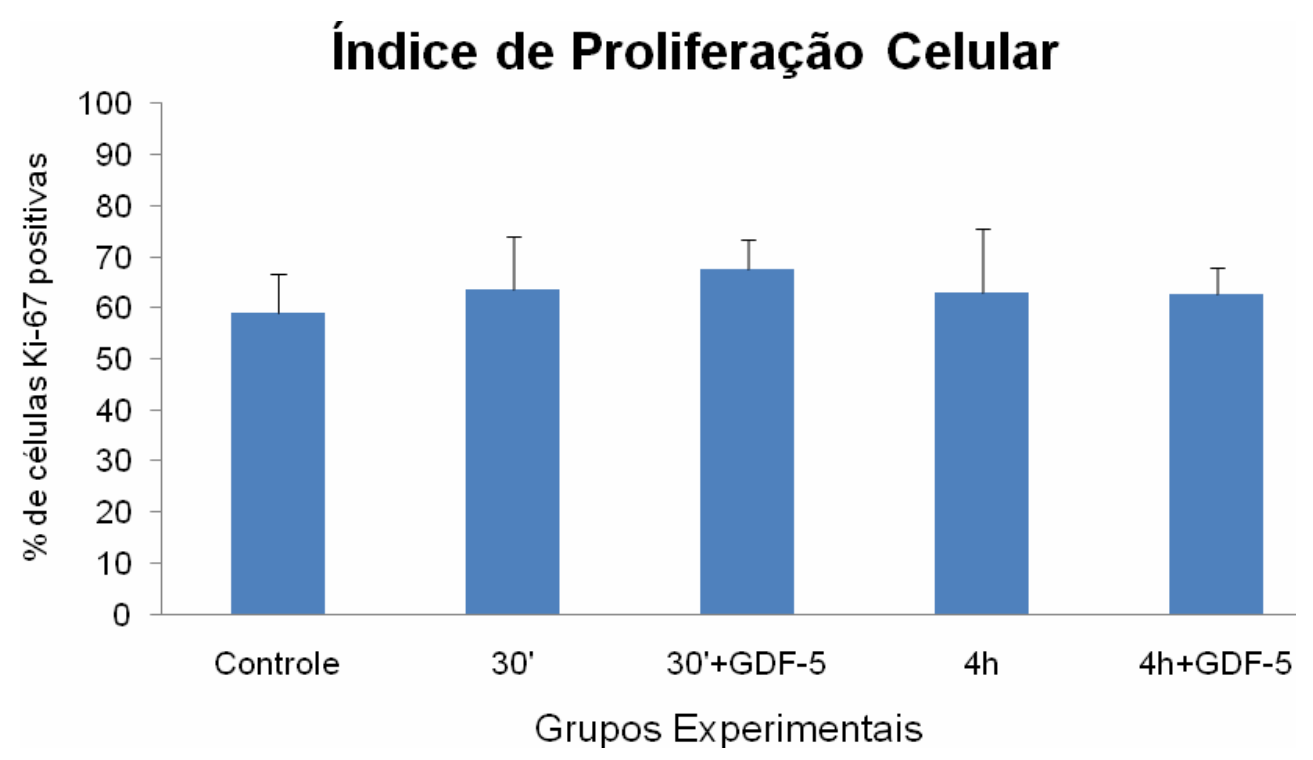

Figura 8. Gráfico de barras do índice de proliferação celular (\% de células Ki-67 positivas) de culturas osteogênicas crescidas sobre as diferentes superfícies de $\mathrm{Ti}$, em 3 dias. Não se observaram diferenças estatisticamente significantes entre os grupos.

\subsection{Número total de células:}

Em 7 dias, todos os grupos com nanotopografia exibiram valores médios maiores de número total de células quando comparados ao Controle. No entanto, a única diferença estatisticamente significante foi observada para a comparação Controle e 4h (Figura 9; Tabelas 2 e 10).

\section{Número Total de Células}

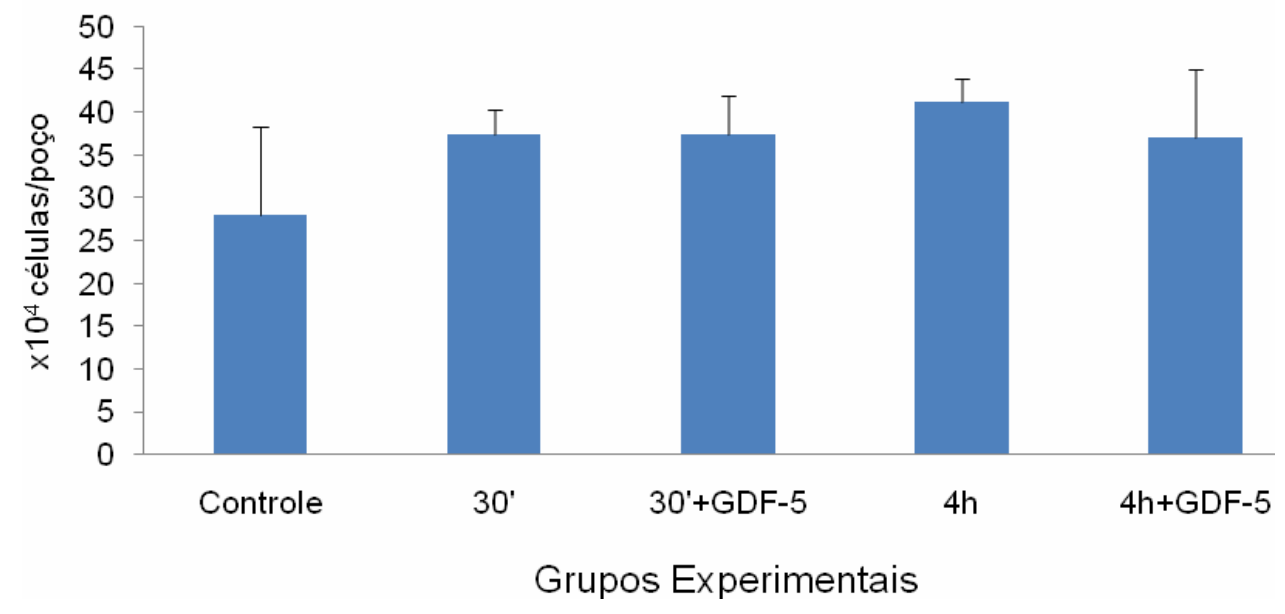

Figura 9. Número total de células osteogênicas crescidas sobre as diferentes superfícies de Ti, em 7 dias. Não se observaram diferenças entre os grupos com nanotopografia. 
Tabela 2 - Análise de variância a um fator de variação (pós-teste de Tukey) referente ao número total de células em 7 dias em culturas osteogênicas sobre as diferentes superfícies de Ti. Os grupos experimentais estão indicados por números, de 1 a 5

\begin{tabular}{|l|l|}
\hline 1 & Controle \\
\hline 2 & 30 \\
\hline 3 & $30{ }^{\prime}+$ GDF-5 \\
\hline 4 & $4 h$ \\
\hline 5 & $4 h+$ GDF-5 \\
\hline
\end{tabular}

\begin{tabular}{|l|l|l|l|l|l|}
\hline & 1 & 2 & 3 & 4 & 5 \\
\hline 1 & & & & $*$ & \\
\hline 2 & & & & & \\
\hline 3 & & & & & \\
\hline 4 & & & & & \\
\hline 5 & & & & & \\
$*$ & $*<0,05$
\end{tabular}

\subsection{Imunolocalização de OPN e BSP:}

Em 3 dias, as células estavam aderidas e espraiadas sobre as diferentes superfícies de Ti, exibindo morfologias poligonais (Figura 10). A OPN localizava-se em região perinuclear na maioria das células espraiadas sobre todas as superfícies, enquanto que acúmulos extracelulares extensos eram observados apenas para os grupos 30 '+GDF-5, 4h e 4h+GDF-5 (Figura 10). Para a nanotopografia obtida por condicionamento por 30', a OPN se acumulava no meio extracelular apenas quando essas superfícies eram pré-adsorvidas com GDF-5.
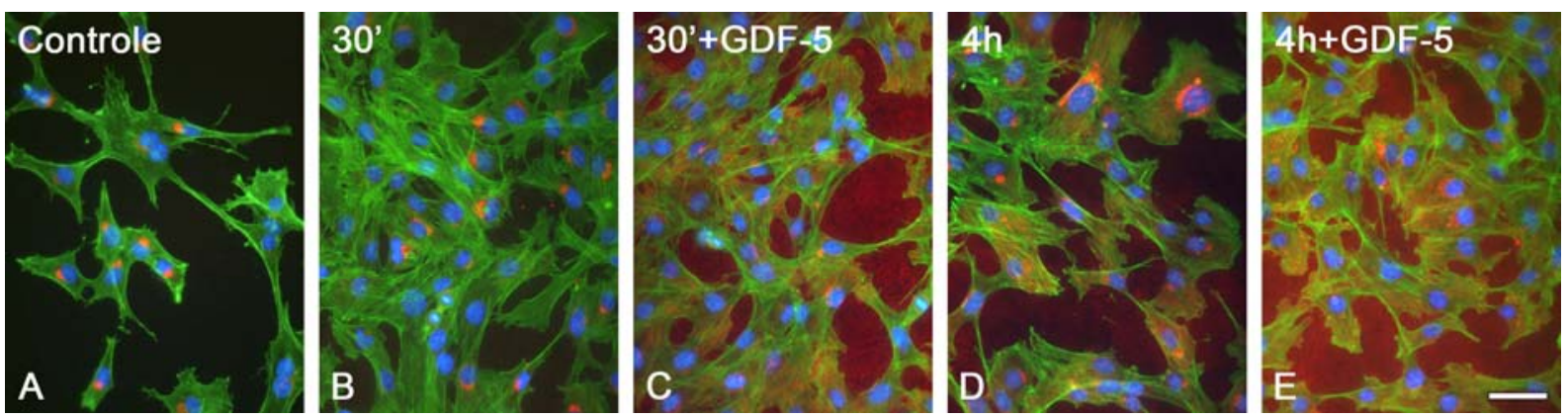

Figura 10. Epifluorescência de culturas osteogênicas crescidas sobre as diferentes superfícies de Ti, em 3 dias (A-E). Marcação em vermelho indica OPN, fluorescência verde revela citoesqueleto de actina e azul, núcleos celulares. Notem-se acúmulos extracelulares de OPN apenas em C-E. Barra = $50 \mu \mathrm{m}$. 
Em 7 dias, ao final da fase proliferativa, todas as culturas crescidas sobre as diferentes superfícies de $\mathrm{Ti}$ exibiam áreas imunomarcadas para $\mathrm{BSP}$, tanto em região perinuclear como extracelularmente, em sua maior parte associadas a formações de multicamadas celulares (Figura 11).
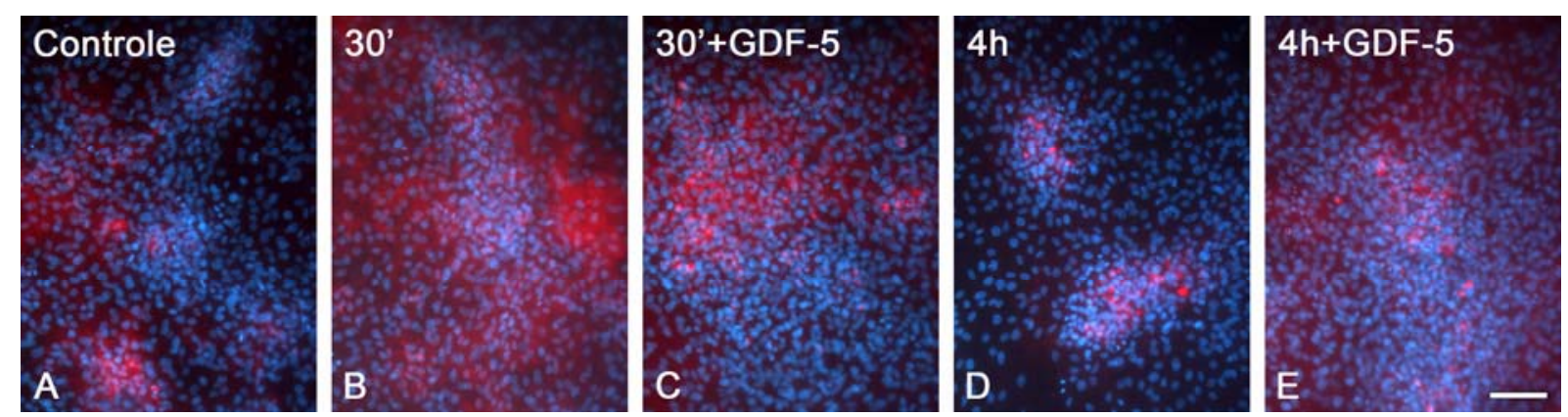

Figura 11. Epifluorescência de culturas osteogênicas crescidas sobre as diferentes superfícies de Ti, em 7 dias (A-E). Marcação em vermelho indica BSP e fluorescência azul, núcleos celulares. Note-se que, em sua maioria, áreas imunomarcadas estão associadas a formações de multicamadas celulares. Barra $=100 \mu \mathrm{m}$.

\subsection{Análise do grau de diferenciação osteoblástica por Real time PCR:}

Para todos os grupos experimentais, a expressão de RUNX2 foi maior em 7 dias quando comparada com 10 dias. Em 7 dias, valores menores foram observados para os grupos de nanotopografia de 30', em comparação ao Controle e à nanotopografia 4h. Em 10 dias, o grupo Controle exibia os maiores valores de RNAm para RUNX2, enquanto que a expressão desse fator de transcrição era significativamente mais baixa para 4h+GDF-5 (Figura 12; Tabelas 3 e 10). 


\section{RUNX2}

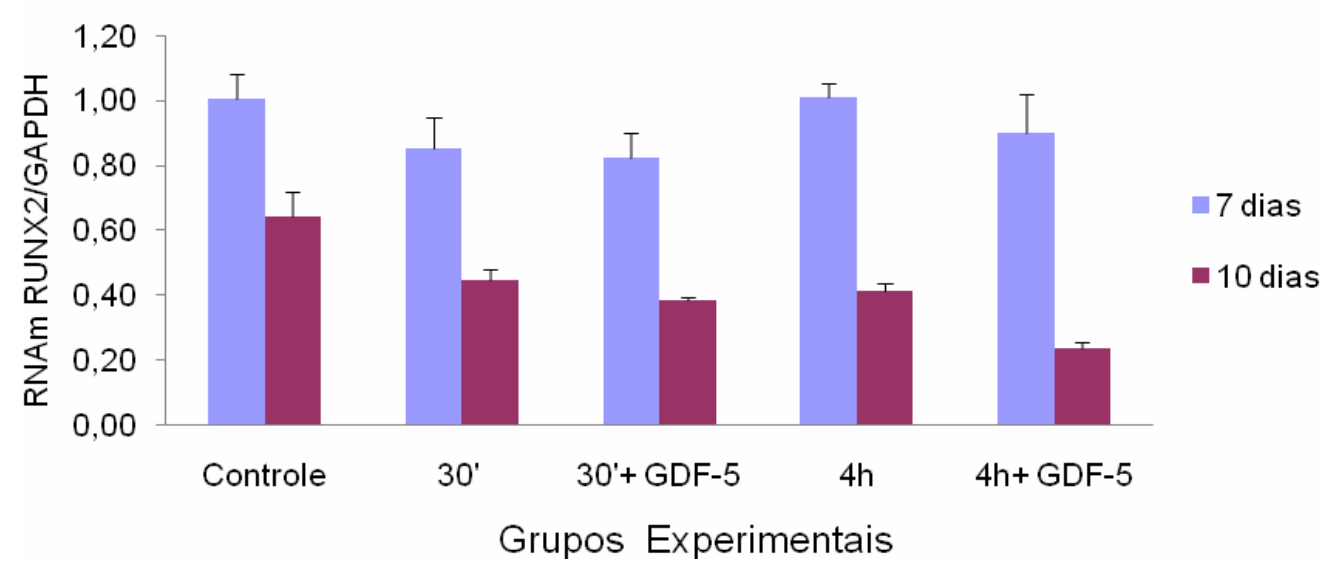

Figura 12. Expressão de RUNX2 em culturas primárias osteogênicas sobre as diferentes superfícies de Ti, em 7 e 10 dias. Os dados foram normalizados pelo gene constitutivo GAPDH, tendo sido atribuído valor 1 para Controle em 7 dias.

Tabela 3 - Análise de variância a dois fatores de variação (pós-teste de Tukey) referente à expressão de RUNX2 em 7 e 10 dias em culturas osteogênicas sobre as diferentes superfícies de Ti. Grupos e tempos experimentais estão indicados por números, de 1 a 10

\begin{tabular}{|c|l|}
\hline 1 & 7 dias - Controle \\
\hline 2 & 7 dias $-30^{\prime}$ \\
\hline 3 & 7 dias $-30^{\prime}+$ GDF-5 \\
\hline 4 & 7 dias $-4 \mathrm{~h}$ \\
\hline 5 & 7 dias $-4 \mathrm{~h}+$ GDF-5 \\
\hline 6 & 10 dias - Controle \\
\hline 7 & 10 dias -30 \\
\hline 8 & 10 dias $-30^{\prime}+$ GDF-5 \\
\hline 9 & 10 dias $-4 \mathrm{~h}$ \\
\hline 10 & 10 dias $-4 \mathrm{~h}+$ GDF-5 \\
\hline
\end{tabular}

\begin{tabular}{|c|c|c|c|c|c|c|c|c|c|}
\hline & 1 & 2 & 3 & 4 & 5 & 6 & 7 & 8 & 10 \\
\hline 1 & & * & * & & & * & * & * & * \\
\hline 2 & & & & & & * & * & * & * \\
\hline 3 & & & & & & * & * & * & * \\
\hline 4 & & * & * & & & * & * & * & * \\
\hline 5 & & & & & & * & * & * & * \\
\hline 6 & & & & & & & * & * & * \\
\hline 7 & & & & & & & & & * \\
\hline 8 & & & & & & & & & * \\
\hline 9 & & & & & & & & & * \\
\hline 10 & & & & & & & & & \\
\hline
\end{tabular}


Os valores de RNAm para ALP foram maiores em 7 dias se comparados a 10 dias, para todos os grupos. Em 7 dias, a expressão de ALP foi significativamente menor para culturas crescidas sobre nanotopografia de 30'. Em 10 dias, a maior expressão de ALP foi observada para Controle, enquanto que 4h+GDF-5 exibiu os menores valores (Figura13; Tabelas 4 e 10).

\section{Fosfatase Alcalina}

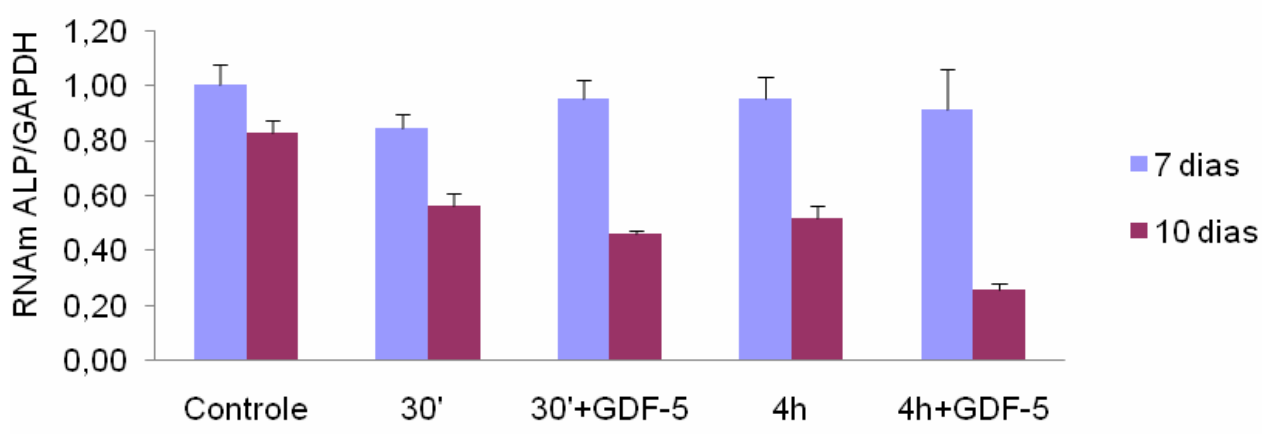

Grupos Experimentais

Figura 13. Expressão de ALP em culturas primárias osteogênicas sobre as diferentes superfícies de Ti, em 7 e 10 dias. Os dados foram normalizados pelo gene constitutivo GAPDH, tendo sido atribuído o valor 1 para grupo controle em 7 dias.

Tabela 4 - Análise de variância a dois fatores de variação (pós-teste de Tukey) referente à expressão de ALP em 7 e 10 dias em culturas osteogênicas sobre as diferentes superfícies de Ti. Grupos e tempos experimentais estão indicados por números, de 1 a 10

\begin{tabular}{|c|l|}
\hline 1 & 7 dias - Controle \\
\hline 2 & 7 dias -30 \\
\hline 3 & 7 dias $-30^{\prime}+$ GDF-5 \\
\hline 4 & 7 dias $-4 \mathrm{~h}$ \\
\hline 5 & 7 dias $-4 \mathrm{~h}+$ GDF-5 \\
\hline 6 & 10 dias - Controle \\
\hline 7 & 10 dias -30 \\
\hline 8 & 10 dias $-30^{\prime}+$ GDF-5 \\
\hline 9 & 10 dias $-4 \mathrm{~h}$ \\
\hline 10 & 10 dias $-4 \mathrm{~h}+$ GDF-5 \\
\hline
\end{tabular}

\begin{tabular}{|c|c|c|c|c|c|c|c|c|c|c|c|}
\hline & 1 & 2 & 3 & 4 & 5 & 6 & 7 & 8 & & & 10 \\
\hline 1 & & * & & & & * & * & * & & & $*$ \\
\hline 2 & & & & & & & * & * & & 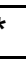 & $*$ \\
\hline 3 & & & & & & * & * & * & & 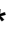 & * \\
\hline 4 & & & & & & * & * & * & & 8 & $*$ \\
\hline 5 & & & & & & & * & * & & 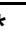 & * \\
\hline 6 & & & & & & & * & 7 & & & * \\
\hline 7 & & & & & & & & & & & * \\
\hline 8 & & & & & & & & & & & $*$ \\
\hline 9 & & & & & & & & & & & $*$ \\
\hline 10 & & & & & & & & & & & \\
\hline
\end{tabular}


Em 7 dias, as culturas crescidas sobre os grupos de nanotopografia 4 h com e sem GDF-5 mostraram os maiores valores de expressão de BSP. Em 10 dias, observou-se redução significativa de RNAm para BSP para todos os grupos com nanotopografias, exceto 30', em que se manteve constante. Os maiores valores foram observados para o Controle, enquanto que os menores, para $4 \mathrm{~h}+\mathrm{GDF}-5$ (Figura14; Tabelas 5 e 10).

\section{Sialoproteína Óssea}

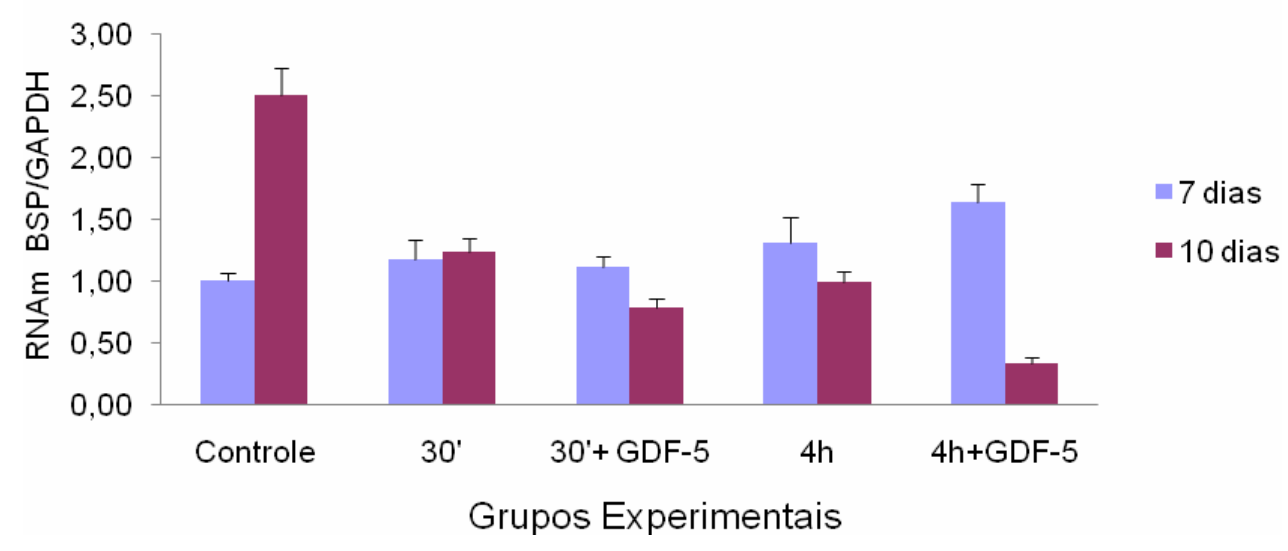

Figura 14. Expressão de BSP em culturas primárias osteogênicas sobre as diferentes superfícies de Ti, em 7 e 10 dias. Os dados foram normalizados pelo gene constitutivo GAPDH, tendo sido atribuído o valor 1 para grupo controle em 7 dias.

Tabela 5 - Análise de variância a dois fatores de variação (pós-teste de Tukey) referente à expressão de BSP em 7 e 10 dias em culturas osteogênicas sobre as diferentes superfícies de Ti. Grupos e tempos experimentais estão indicados por números, de 1 a 10

\begin{tabular}{|c|l|}
\hline 1 & 7 dias - Controle \\
\hline 2 & 7 dias -30 \\
\hline 3 & 7 dias -30 ' + GDF-5 \\
\hline 4 & 7 dias $-4 h$ \\
\hline 5 & 7 dias $-4 h+$ GDF-5 \\
\hline 6 & 10 dias - Controle \\
\hline 7 & 10 dias -30 \\
\hline 8 & 10 dias -30 ' + GDF-5 \\
\hline 9 & 10 dias $-4 h$ \\
\hline 10 & 10 dias $-4 h+$ GDF-5 \\
\hline
\end{tabular}

\begin{tabular}{|c|c|c|c|c|c|c|c|c|c|c|}
\hline & 1 & 2 & 3 & 4 & 5 & 6 & 7 & 8 & 9 & 10 \\
\hline 1 & & & & & & & & & & * \\
\hline 2 & & & & & & & & * & & * \\
\hline 3 & & & & & & & & * & & * \\
\hline 4 & * & & & & & & & * & * & * \\
\hline 5 & * & * & * & * & & & $*$ & * & * & * \\
\hline 6 & * & * & * & * & * & & * & * & * & * \\
\hline 7 & & & & & & & & * & & * \\
\hline 8 & & & & & & & & & & * \\
\hline 9 & & & & & & & & & & * \\
\hline 10 & & & & & & & & & & \\
\hline
\end{tabular}


A expressão de RNAm para OPN não mostrou diferenças estatisticamente significantes entre os grupos em 7 dias. Em 10 dias, os valores foram significativamente maiores se comparados a 7, exceção para 30'+GDF-5. A adsorção de GDF-5 reduziu a expressão de OPN nas culturas em 10 dias, quando comparadas a seus respectivos controles (Figura15; Tabelas 6 e 10).

\section{Osteopontina}

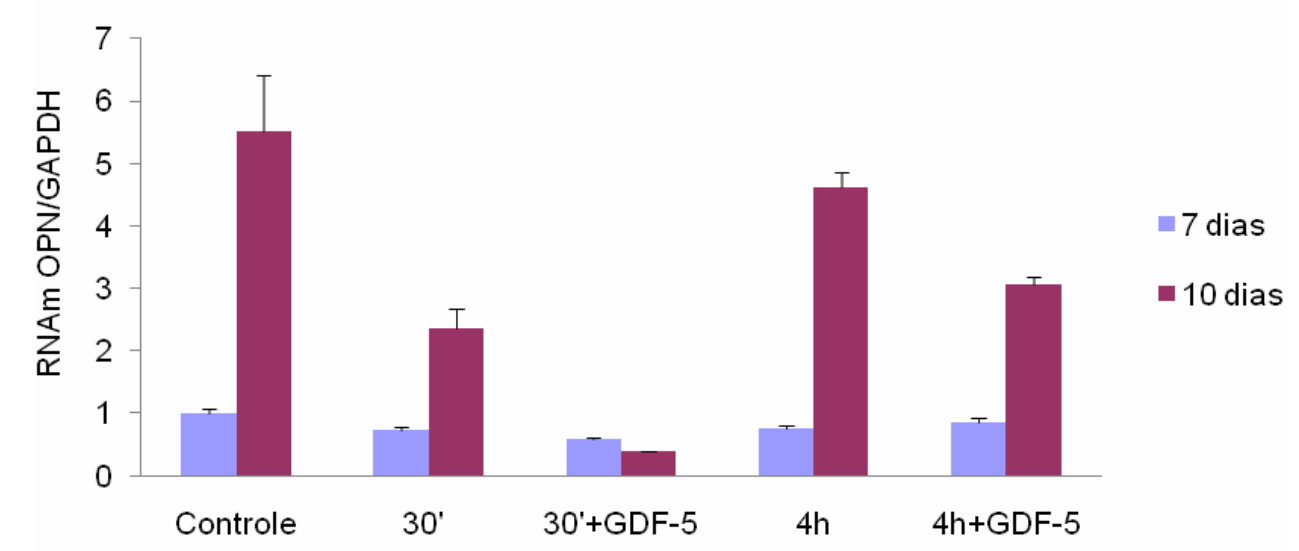

Grupos Experimentais

Figura 15. Expressão de OPN em culturas primárias osteogênicas sobre as diferentes superfícies de Ti, em 7 e 10 dias. Os dados foram normalizados pelo gene constitutivo GAPDH, tendo sido atribuído valor 1 para Controle em 7 dias.

Tabela 6 - Análise de variância a dois fatores de variação (pós-teste de Tukey) referente à expressão de OPN em 7 e 10 dias em culturas osteogênicas sobre as diferentes superfícies de Ti. Grupos e tempos experimentais estão indicados por números, de 1 a 10

\begin{tabular}{|c|l|}
\hline 1 & 7 dias - Controle \\
\hline 2 & 7 dias $-30^{\prime}$ \\
\hline 3 & 7 dias $-30^{\prime}+$ GDF-5 \\
\hline 4 & 7 dias $-30^{\prime}+$ GDF-5 \\
\hline 5 & 7 dias -4 h+GDF-5 \\
\hline 6 & 10 dias - Controle \\
\hline 7 & 10 dias $-30^{\prime}$ \\
\hline 8 & 10 dias $-30^{\prime}+$ GDF-5 \\
\hline 9 & 10 dias -4 h \\
\hline 10 & 10 dias -4 h+GDF-5 \\
\hline
\end{tabular}

\begin{tabular}{|c|c|c|c|c|c|c|c|c|c|c|}
\hline & 1 & 2 & 3 & 4 & 5 & 6 & 7 & 8 & 9 & 10 \\
\hline 1 & & & & & & & & $*$ & & \\
\hline 2 & & & & & & & & & & \\
\hline 3 & & & & & & & & & & \\
\hline 4 & & & & & & & & & & \\
\hline 5 & & & & & & & & & & \\
\hline 6 & ${ }^{*}$ & $*$ & $*$ & $*$ & $*$ & & ${ }^{*}$ & ${ }^{*}$ & & ${ }^{*}$ \\
\hline 7 & ${ }^{*}$ & ${ }^{*}$ & ${ }^{*}$ & $*$ & $*$ & $*$ & & ${ }^{*}$ & & \\
\hline 8 & & & & & & $*$ & & & & \\
\hline 9 & ${ }^{*}$ & ${ }^{*}$ & ${ }^{*}$ & ${ }^{*}$ & ${ }^{*}$ & & ${ }^{*}$ & ${ }^{*}$ & & ${ }^{*}$ \\
\hline 10 & ${ }^{*}$ & ${ }^{*}$ & ${ }^{*}$ & ${ }^{*}$ & ${ }^{*}$ & ${ }^{*}$ & ${ }^{*}$ & ${ }^{*}$ & ${ }^{*}$ & \\
\hline
\end{tabular}




\subsection{Atividade de ALP:}

A atividade de ALP aumentou significativamente de 7 para 10 dias em todos os grupos. Enquanto que em 7 dias não houve diferenças entre os grupos, em 10 dias os maiores valores ocorreram para Controle e nanotopografias funcionalizadas com GDF-5 (Figura16; Tabelas 7 e 10).

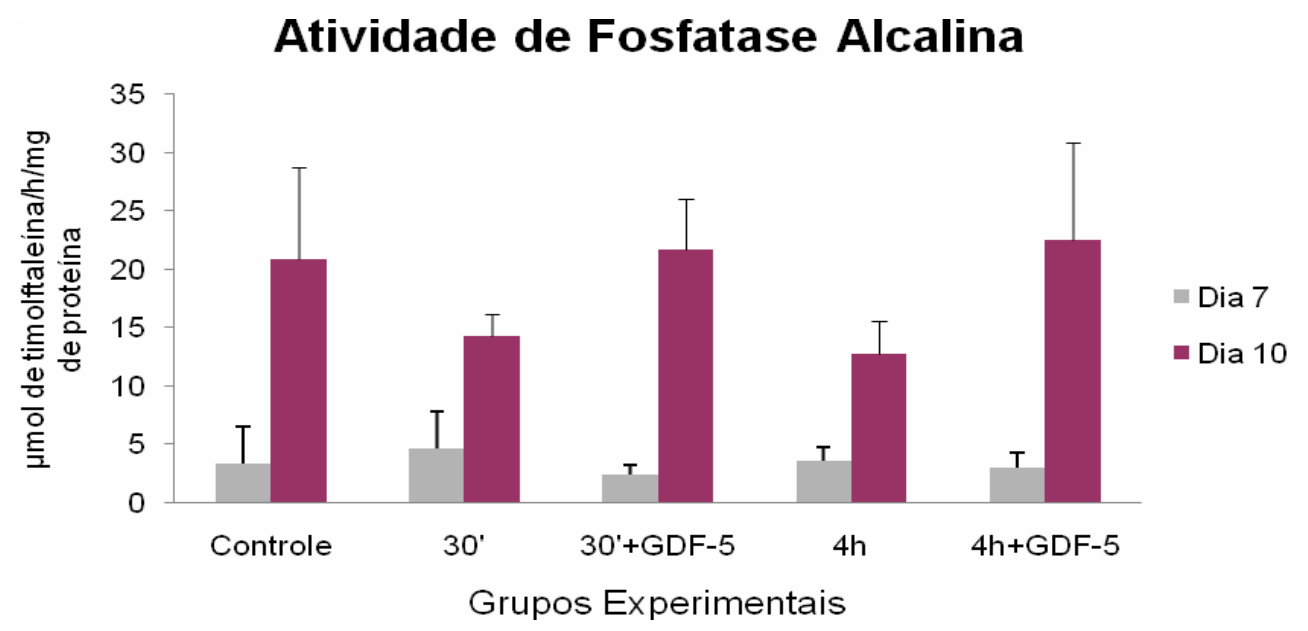

Figura 16. Atividade de ALP (em $\mu \mathrm{mol}$ de timolftaleína/h/mg de proteína) de culturas primárias osteogênicas crescidas sobre as diferentes superfícies de $\mathrm{Ti}$, em 7 e 10 dias.

Tabela 7 - Análise de variância a dois fatores de variação (pós-teste de Tukey) referente à atividade de ALP em 7 e 10 dias em culturas osteogênicas sobre as diferentes superfícies de Ti. Grupos e tempos experimentais estão indicados por números, de 1 a 10

\begin{tabular}{|c|l|}
\hline 1 & 7 dias - Controle \\
\hline 2 & 7 dias -30 \\
\hline 3 & 7 dias -30 ' + GDF-5 \\
\hline 4 & 7 dias -30 ' + GDF-5 \\
\hline 5 & 7 dias -4 h+GDF-5 \\
\hline 6 & 10 dias - Controle \\
\hline 7 & 10 dias -30 \\
\hline 8 & 10 dias -30 'GDF-5 \\
\hline 9 & 10 dias $-4 h$ \\
\hline 10 & 10 dias $-4 h+$ GDF-5 \\
\hline
\end{tabular}

\begin{tabular}{|l|l|l|l|l|l|l|l|l|l|l|}
\hline & 1 & 2 & 3 & 4 & 5 & 6 & 7 & 8 & 9 & 10 \\
\hline 1 & & & & & & & & & & \\
\hline 2 & & & & & & & & & & \\
\hline 3 & & & & & & & & & & \\
\hline 4 & & & & & & & & & & \\
\hline 5 & & & & & & & & & & \\
\hline 6 & $*$ & $*$ & $*$ & $*$ & $*$ & & & & & \\
\hline 7 & $*$ & $*$ & $*$ & $*$ & $*$ & & & & & \\
\hline 8 & $*$ & $*$ & $*$ & $*$ & $*$ & & & & & \\
\hline 9 & & & $*$ & $*$ & $*$ & & & & & \\
\hline 10 & $*$ & $*$ & $*$ & $*$ & $*$ & & & & $*$ & \\
\hline
\end{tabular}




\subsection{Formação de matriz mineralizada:}

Em 14 dias, a coloração com ARS revelou, para todos os grupos, formações nodulares típicas de matriz mineralizada, castanho-avermelhadas, circundadas por áreas de mineralização difusa, de cor avermelhada, de extensão variável (Figura 17). Quantitativamente, as culturas sobre $4 \mathrm{~h}$ e $4 \mathrm{~h}+\mathrm{GDF}-5$ mostraram áreas mais extensas de mineralização em comparação ao Controle, sem diferenças entre os grupos com GDF-5 e seus respectivos controles (Figura 18; Tabelas 8 e 10). No entanto, a extração de ARS permitiu identificar valores estatisticamente maiores para culturas crescidas sobre nanotopografias com GDF-5 em comparação com seus controles, 30' e 4h. (Figura 19; Tabelas 9 e 10).
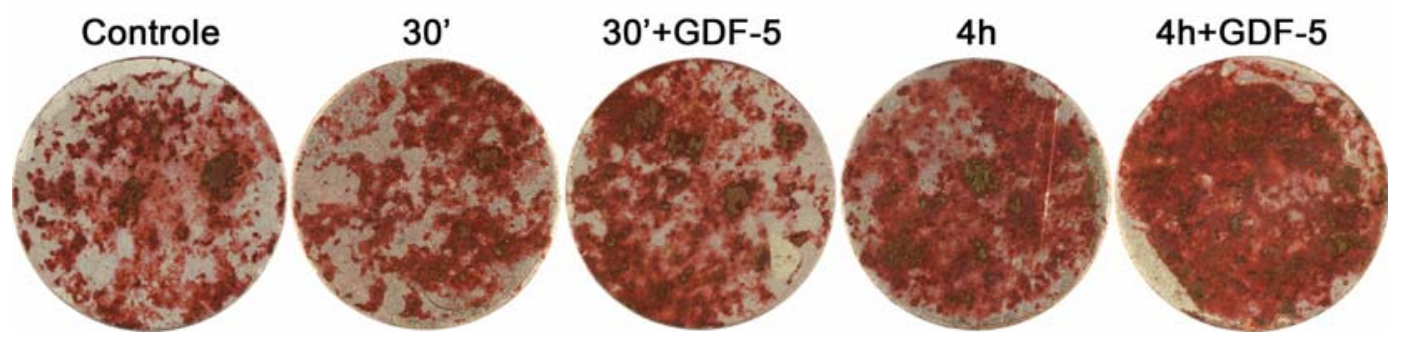

Figura 17. Aspecto macroscópico de culturas osteogênicas sobre as diferentes superfícies de Ti, em 14 dias, coradas com ARS, para detecção de acúmulos de cálcio.

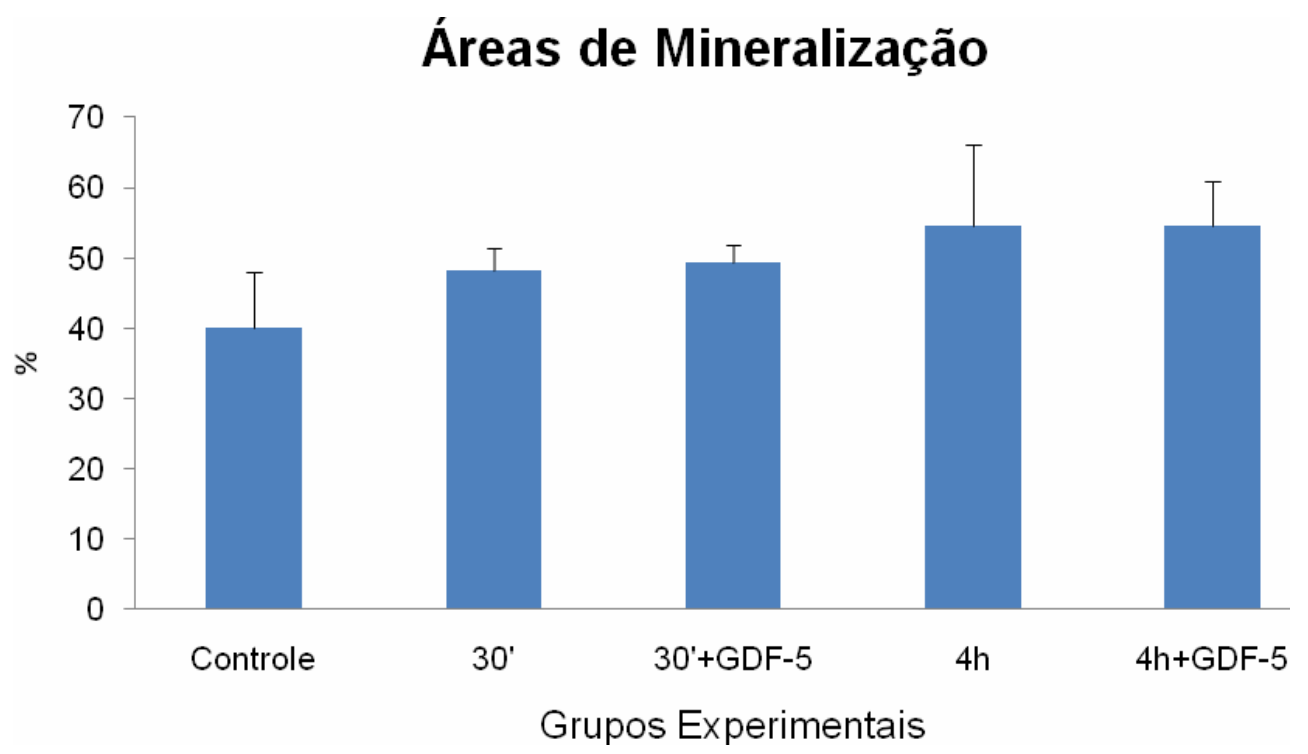

Figura 18. Porcentagem de área total corada com ARS em culturas osteogênicas sobre as diferentes superfícies de $\mathrm{Ti}$, em 14 dias. Áreas mais extensas foram observadas para os grupos $4 \mathrm{~h}$ e $4 \mathrm{~h}+\mathrm{GDF}-5$, em comparação com Controle. 
Tabela 8 - Análise de variância a um fator de variação (pós-teste de Tukey) referente à porcentagem de área total corada com ARS em culturas osteogênicas sobre as diferentes superfícies de Ti, em 14 dias. Os grupos experimentais estão indicados por números, de 1 a 5

\begin{tabular}{|l|l|}
\hline 1 & Controle \\
\hline 2 & $30^{\prime}$ \\
\hline 3 & $30^{\prime}+$ GDF-5 \\
\hline 4 & $4 \mathrm{~h}$ \\
\hline 5 & $4 \mathrm{~h}+$ GDF-5 \\
\hline
\end{tabular}

\begin{tabular}{|l|l|l|l|l|l|}
\hline & 1 & 2 & 3 & 4 & 5 \\
\hline 1 & & & & & \\
\hline 2 & & & & & \\
\hline 3 & & & & & \\
\hline 4 & $*$ & & & & \\
\hline 5 & $*$ & & & & \\
\hline \multicolumn{5}{|c|}{$* 00,05$} \\
\end{tabular}

\section{Extração de Vermelho de Alizarina}

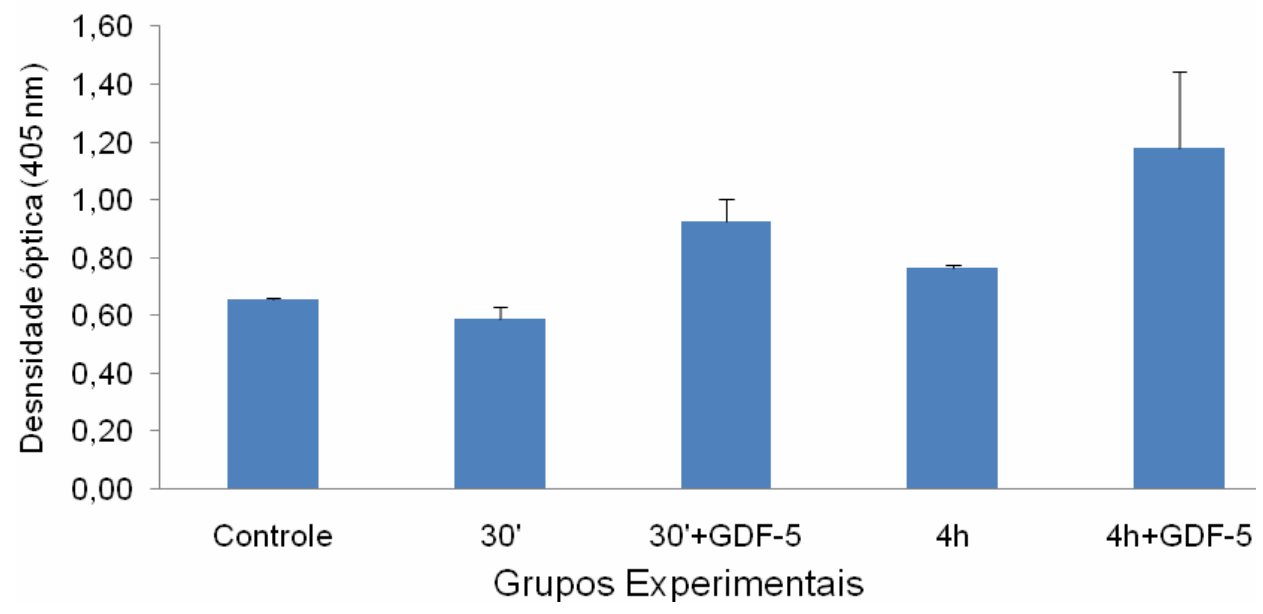

Figura 19. Quantificação de ARS (em valores de densidade óptica) de culturas osteogênicas sobre as diferentes superfícies de Ti, em 14 dias. Notem-se valores maiores para os grupos de nanotopografia com GDF-5, comparados com seus respectivos controles.

Tabela 9 - Análise de variância a um fator de variação (pós-teste de Tukey) referente à quantificação de ARS de culturas osteogênicas sobre as diferentes superfícies de Ti, em 14 dias. Os grupos experimentais estão indicados por números, de 1 a 5

\begin{tabular}{|l|l|}
\hline 1 & Controle \\
\hline 2 & $30^{\prime}$ \\
\hline 3 & $30^{\prime}+$ GDF-5 \\
\hline 4 & $4 \mathrm{~h}$ \\
\hline 5 & $4 \mathrm{~h}+$ GDF-5 \\
\hline
\end{tabular}

\begin{tabular}{|l|l|l|l|l|l|}
\hline & 1 & 2 & 3 & 4 & 5 \\
\hline 1 & & & & & \\
\hline 2 & & & & & \\
\hline 3 & & $*$ & & & \\
\hline 4 & & & & & \\
\hline 5 & $*$ & $*$ & & $*$ & \\
\hline \multicolumn{6}{c|}{ * $<0,05$}
\end{tabular}


Tabela 10 - Análises quantitativas de adesão e espraiamento celular, proliferação, número total de células, viabilidade celular, expressão gênica, atividade de ALP, áreas de mineralização e extração de ARS de culturas osteogênicas crescidas sobre superfícies de titânio Controle, 30', 30'+GDF-5, 4h e $4 h+G D F-5$

\begin{tabular}{|c|c|c|c|c|c|c|c|}
\hline Parâmetros & Tempo & Controle & 30 & $30 '+G D F-5$ & $4 h$ & $4 h+G D F-5$ & $P$ \\
\hline \multirow{2}{*}{$\begin{array}{l}\text { Adesão e espraiamento } \\
\text { celular (Estágios } 1 \text { e } 2 ; 3 \text { e } 4 \text {; } \\
\% \text { ) }\end{array}$} & \multirow{2}{*}{$4 \mathrm{~h}$} & $60,3 \pm 7,7$ & $53,2 \pm 9,4$ & $73,4 \pm 4,5$ & $47,2 \pm 4,1$ & $79+5,3$ & $<0,05$ \\
\hline & & $39,7 \pm 7,7$ & $46,8 \pm 9,4$ & $26,6 \pm 4,5$ & $52,8 \pm 4,1$ & $21 \pm 5,3$ & $<0,05$ \\
\hline Proliferação (Ki-67; \%) & $3 d$ & $59 \pm 7,6$ & $63,7 \pm 10,3$ & $67,8 \pm 5,7$ & $63 \pm 12,5$ & $62,8 \pm 5,2$ & NS \\
\hline \multirow[t]{2}{*}{ Número total de células } & $7 d$ & $28 \pm 10,3$ & $37,5 \pm 2,8$ & $37,5 \pm 4,5$ & $41,3 \pm 2,7$ & $37 \pm 8$ & $<0,05$ \\
\hline & $1 d$ & $0,048 \pm 0,018$ & $0,054 \pm 0,009$ & $0,067 \pm 0,013$ & $0,036 \pm 0,004$ & $0,026 \pm 0,012$ & NS \\
\hline \multirow[t]{2}{*}{ Viabilidade celular } & $3 d$ & $0,089 \pm 0,035$ & $0,078 \pm 0,017$ & $0,073 \pm 0,007$ & $0,079 \pm 0,012$ & $0,084 \pm 0,023$ & NS \\
\hline & $7 d$ & $0,262 \pm 0,038$ & $0,225 \pm 0,032$ & $0,265 \pm 0,030$ & $0,26 \pm 0,073$ & $0,256 \pm 0,026$ & NS \\
\hline \multirow{2}{*}{ Expressão RNAm de RUNX2 } & $7 d$ & $1,002 \pm 0,077$ & $0,85 \pm 0,098$ & $0,823 \pm 0,075$ & $1,009 \pm 0,041$ & $0,9 \pm 0,116$ & $<0,05$ \\
\hline & $10 \mathrm{~d}$ & $0,64 \pm 0,076$ & $0,445 \pm 0,035$ & $0,384 \pm 0,01$ & $0,415 \pm 0,02$ & $0,238 \pm 0,019$ & $<0,05$ \\
\hline \multirow{2}{*}{ Expressão RNAm de ALP } & $7 d$ & $1,002 \pm 0,076$ & $0,847 \pm 0,046$ & $0,953 \pm 0,066$ & $0,953 \pm 0,078$ & $0,910 \pm 0,149$ & $<0,05$ \\
\hline & $10 \mathrm{~d}$ & $0,827 \pm 0,043$ & $0,561 \pm 0,046$ & $0,459 \pm 0,014$ & $0,516 \pm 0,048$ & $0,258 \pm 0,02$ & $<0,05$ \\
\hline \multirow{2}{*}{ Expressão RNAm de BSP } & $7 d$ & $1,001 \pm 0,065$ & $1,173 \pm 0,164$ & $1,11 \pm 0,09$ & $1,315 \pm 0,2$ & $1,64 \pm 0,15$ & $<0,05$ \\
\hline & $10 \mathrm{~d}$ & $2,514 \pm 0,21$ & $1,236 \pm 0,115$ & $0,787 \pm 0,076$ & $0,993 \pm 0,084$ & $0,331 \pm 0,056$ & $<0,05$ \\
\hline \multirow{2}{*}{ Expressão RNAm de OPN } & $7 d$ & $1,001 \pm 0,065$ & $0,726 \pm 0,065$ & $0,582 \pm 0,034$ & $0,752 \pm 0,052$ & $0,862 \pm 0,055$ & $<0,05$ \\
\hline & $10 \mathrm{~d}$ & $5,522 \pm 0,895$ & $2,353 \pm 0,313$ & $0,384 \pm 0,01$ & $4,605 \pm 0,257$ & $3,065 \pm 0,129$ & $<0,05$ \\
\hline \multirow{2}{*}{ Atividade de ALP } & $7 d$ & $3,3 \pm 3,2$ & $4,7 \pm 3,2$ & $2,4 \pm 0,8$ & $3,6 \pm 1,2$ & $2,9 \pm 1,3$ & NS \\
\hline & $10 d$ & $20,8 \pm 7,9$ & $14,3 \pm 1,9$ & $21,7 \pm 4,4$ & $12,8 \pm 2,9$ & $22,6 \pm 8,4$ & $<0,05$ \\
\hline Áreas de mineralização & $14 d$ & $40 \pm 7,9$ & $48,3 \pm 3$ & $49,4 \pm 2,4$ & $54,6 \pm 11,5$ & $54,5 \pm 6,4$ & $<0.05$ \\
\hline Extração de ARS & $14 \mathrm{~d}$ & $0,654 \pm 0,007$ & $0,59 \pm 0,04$ & $0,92 \pm 0,078$ & $0,76 \pm 0,009$ & $1,181 \pm 0,265$ & $<0,05$ \\
\hline
\end{tabular}

NS: Não significante 


\section{DISCUSSÃO:}

Os resultados do presente estudo mostraram que a simples adsorção de GDF-5 sobre superfícies de Ti com nanotopografias altera aspectos importantes do processo de aquisição do fenótipo osteogênico in vitro. Menor espraiamento celular em 4 h e, em 10 dias, redução na expressão de RUNX2, ALP e BSP e aumento da atividade de ALP precederam o aumento de acúmulos de cálcio durante a fase de mineralização de culturas primárias de células osteoblásticas. O tempo de condicionamento de $4 \mathrm{~h}$ resultou em atividade osteogênica significativamente maior para as culturas expostas ao GDF-5 em comparação ao de 30'.

Diferentes estratégias vêm sendo desenvolvidas com o objetivo de disponibilizar moléculas bioativas na interface biomaterial-tecido biológico para o controle das interações iniciais de células e proteínas plasmáticas e da matriz extracelular com a superfície de implantes (MORRA et al. 2006; MENDONÇA et al. 2008; BEUTNER et al. 2010; RICHERT et al. 2010), o que inclui a funcionalização por simples adsorção ou por ligações covalentes. No presente trabalho, optou-se pelo método de simples adsorção, de menor complexidade e de baixo custo, ainda que potencialmente capaz de produzir efeitos biológicos relevantes dependendo da proteína utilizada (O'TOOLE et al. 2004; GARCIA \& REYES 2005 et al; WIKESJÖ et al. 2008; SCHOUTEN et al. 2009).

A escolha pelo GDF-5 baseou-se no fato desse fator de crescimento estimular células indiferenciadas de tecidos conjuntivos a diferenciar-se em células da linhagem osteoblástica, em mecanismo semelhante à ação de BMPs via Smads (NISHITOH et al. 1996; YOSHIMOTO et al. 2006). De fato, o GDF-5 é uma isoforma 
dos GDFs, os quais, juntamente com as BMPs, fazem parte da superfamília do TGF$\beta$ (FRANCIS-WEST et al. 1999; KUNIYASU et al. 2003; YOSHIMOTO et al. 2006). Além disso, o GDF-5 tem efeito conhecido sobre a ALP, promovendo o aumento de sua atividade (SHIMAOKA et al. 2004). No tecido ósseo, a ALP está confinada à superfície de osteoblastos, incluindo as membranas das vesículas de matriz que essas células secretam, nas quais a ALP é particularmente mais concentrada. Apesar de se propor que o principal efeito da ALP é fornecer fosfato necessário para formação de hidroxiapatita para sua ligação com a matriz colágena, sugere-se, também, que a ALP hidrolise o inibidor de mineralização pirofosfato, facilitando a precipitação mineral e a formação da matriz óssea (MILLÁN 2006). Portanto, o aumento de atividade de ALP nas culturas estimuladas pela funcionalização com GDF-5 poderia alterar o equilíbrio fosfato/pirofosfato, o qual é considerado fator determinante para a mineralização da matriz extracelular.

Como o fenômeno de adsorção de proteínas sobre substratos sólidos é afetado pelos aspectos topográficos de superfície na nanoescala, podendo alterar a orientação e a conformação de proteínas (LORD et al. 2010; RICHERT et al. 2010) e, consequentemente, a sinalização celular, decidiu-se por avaliar o impacto do tempo de condicionamento da superfície de Ti sobre a adsorção de GDF-5 e seus efeitos sobre parâmetros importantes do desenvolvimento do fenótipo osteogênico in vitro. Com efeito, alterações nos aspectos nanotopográficos de superfícies metálicas condicionadas por $\mathrm{H}_{2} \mathrm{SO}_{4} / \mathrm{H}_{2} \mathrm{O}_{2}$ podem ser obtidos quando se variam o tempo e a temperatura de condicionamento, bem como as proporções relativas entre ácidos (ou mesmo bases) e soluções oxidantes (VARIOLA et al. 2009; VETRONE et al. 2009). No presente estudo, a análise qualitativa por MEV de alta resolução mostrou que nanocavidades de dimensões maiores formavam-se após o condicionamento de 
4h, mas não de 30', e que os aspectos topográficos de nanocavidades mantinhamse aparentemente inalterados com a adsorção de GDF-5 na concentração utilizada (200 ng/mL). Análise preliminar por microscopia de força atômica revelou valores de nanorugosidade (RMS, root mean square) para área de $1 \times 1 \mu \mathrm{m}^{2}$ variando entre $4 \mathrm{e}$ $8 \mathrm{~nm}$ para os diferentes grupos experimentais (Controle, 4,8 nm; 30', 5,9 nm; 30'+GDF-5, 5,2 nm; 4h, 7,6 nm; 4h+GDF-5, 6,4 nm). As diferenças entre os condicionamentos de $30^{\prime}$ e 4 h por si só resultaram em modificações na progressão das culturas osteogênicas, possivelmente devido à própria nanotopografia ou à adsorção diferencial de proteínas do soro presentes no meio de cultura. Além disso, alterações em determinados parâmetros atribuídas à disponibilização do GDF-5, como a expressão de OPN em 10 dias, foram claramente afetadas pelo tempo de condicionamento das superfícies de Ti, provavelmente modificando a adsorção de GDF-5. Estudos posteriores deveriam avaliar os diferentes aspectos do processo de adsorção de proteínas sobre nanotopografias de Ti, utilizando, por exemplo, o método IRRAS (infrared reflection-absorption spectroscopy; MENDELSOHN et al. 2010), de grande importância e versatilidade para a compreensão das interações de moléculas orgânicas com substratos metálicos (TRANSFERETTI \& DAVANZO 2001).

Um dos métodos quantitativos utilizados para avaliar a atividade osteogênica in vitro sobre os diferentes substratos de Ti foi a análise da expressão de RNAm de marcadores da diferenciação osteoblástica em 7 e 10 dias das culturas primárias, que representam, para substratos planos na micro e nanoescala, o final da fase proliferativa e o início do processo de mineralização da MEC, respectivamente. Nesse modelo experimental, com a adição de ácido ascórbico e beta-glicerofosfato, desenvolvem-se formações nodulares mineralizadas semelhantes ao tecido ósseo 
imaturo, as quais resultam da expansão clonal de células osteoprogenitoras e da subsequente aquisição do fenótipo osteoblástico (NANCl et al. 1996; BELLOWS et al.1986; BELLOWS et al. 1989; STEIN et al. 1993). O potencial osteogênico das culturas está, portanto, diretamente relacionado ao recrutamento seletivo de células indiferenciadas, à taxa de proliferação de células osteoprogenitoras, ao número de osteoblastos ativos e a seu tempo de vida/atividade, bem como à estimulação da atividade de síntese dessas células (revisado por DE OLIVEIRA et al. 2007). Qualquer variação que ocorra nesses aspectos, determinada pelos diferentes substratos, pode se refletir no perfil de expressão de marcadores da diferenciação osteoblástica, tanto iniciais (por exemplo, RUNX2, ALP e BSP) como de fases mais avançadas (por exemplo, OPN e osteocalcina). Assim, qualquer análise da expressão de marcadores osteoblásticos deveria, idealmente, ser realizada conjuntamente com a avaliação do potencial osteogênico das culturas.

Em relação à expressão dos marcadores iniciais, os resultados deste estudo mostraram valores maiores de RUNX2, ALP e BSP em 10 dias para o Controle, de menor potencial osteogênico, enquanto que a menor expressão desses marcadores ocorreu para 4h+GDF-5, que estimulava a mineralização, sugerindo aceleração da aquisição do fenótipo osteoblástico. Essa interpretação reforça-se quando se consideram a menor expressão de RUNX2, ALP e BSP e a maior de OPN em 10 dias para as culturas expostas ao GDF-5, cujos valores de extração de ARS foram maiores do que os de seus respectivos controles. Assim, os picos de expressão dos marcadores iniciais, esperados para culturas de alto potencial osteogênico, teriam ocorrido possivelmente em tempos anteriores ao de 10 dias, não avaliados neste estudo. Dos marcadores iniciais utilizados, apenas a expressão de BSP em 7 dias correlacionava-se positivamente com o maior potencial osteogênico das culturas 
sobre 4h+GDF-5. Em relação à ALP, cuja expressão/atividade é reconhecidamente afetada pelo GDF-5 (SHIMAOKA et al. 2004), não se detectaram diferenças na expressão de RNAm sobre nanotopografias funcionalizadas com esse fator. No entanto, a atividade de ALP foi significativamente maior em 10 dias para esses grupos, correlacionando-se positivamente com a maior mineralização da MEC.

Culturas osteogênicas sobre superfícies de Ti com nanotopografia exibem abundante marcação extracelular para OPN em tempos iniciais pós-plaqueamento (DE OLIVEIRA \& NANCI 2004; DE OLIVEIRA et al. 2007; VETRONE et al. 2009). Apesar de não se ter esclarecido se isso ocorre por aumento da adsorção dessa proteína ao substrato nanoestruturado, por aumento de sua secreção ou ambos os fatores, esse fenômeno parece estar intimamente ligado ao aumento de áreas de mineralização dessas culturas. No presente estudo, observou-se que a nanotopografia de 30' não favoreceu a formação de acúmulos extracelulares de OPN, os quais eram observados para essa nanotopografia apenas com a adsorção de GDF-5, quando se obtinham valores maiores de extração de ARS.

Os resultados das análises morfológica e bioquímica com ARS não foram coincidentes. Maiores proporções de áreas coradas em vermelho ocorreram nos grupos $4 h$ e $4 h+G D F-5$, o que poderia ser atribuído ao efeito da nanotopografia obtida pelo condicionamento com $\mathrm{H}_{2} \mathrm{SO}_{4} / \mathrm{H}_{2} \mathrm{O}_{2}$ por $4 \mathrm{~h}$. No entanto, a análise bioquímica revelou valores maiores de extração de ARS para as nanotopografias com GDF-5, ficando evidente que, com essa análise, o GDF-5 teve uma influência maior do que as nanotopografias obtidas pelos dois tempos de condicionamento. Uma explicação possível estaria ligada a acúmulos maiores de cálcio em formações nodulares mais espessas das culturas expostas ao GDF-5, indicando maior atividade de células osteoblásticas nessas condições de cultivo. 


\section{CONCLUSÃO:}

Conclui-se que a funcionalização de nanotopografias de $\mathrm{Ti}$ por simples adsorção de GDF-5 pode estimular o desenvolvimento do fenótipo osteogênico em culturas primárias de calvárias de ratos, aumentando a atividade de ALP e o processo de mineralização da MEC. A nanotopografia por condicionamento de $4 \mathrm{~h}$ parece favorecer os eventos finais da cultura quando comparada com a de 30 '. Estudos posteriores em modelos animais deverão avaliar a relevância de se utilizar tal estratégia visando a favorecer a osseointegração de implantes metálicos, sobretudo em áreas de baixa qualidade óssea e com carga imediata. 


\section{REFERÊNCIAS BIBLIOGRÁFICAS}

Bellows CG, Aubin JE, Heersche JNM, Antosz ME. Mineralized bone nodules formed in vitro from enzymatically released rat calvaria cell populations. Calcif Tissue Int 1986;38:143-154.

Bellows CG, Aubin JE. Determination of numbers of osteoprogenitors present in isolated fetal rat calvaria cells in vitro. Dev Biol 1989;133:8-13.

Beutner R, Michael J, Schwenzer B, Scharnweber D. Biological nanofunctionalization of titanium-based biomaterial surfaces: a flexible toolbox. J R Soc Interface 2010;7:S93-S105.

Bornstein MM, Cionca N, Mombelli A. Systemic conditions and treatments as risks for implant therapy. Int J Oral Maxillofac Implants 2009;24 Suppl:12-27.

Davies JE. Mechanisms of endosseous integration. Int J Prosthodont 1998;11:391401.

De Oliveira PT, Zalzal SF, Irie K, Nanci A. Early expression of bone matrix proteins in osteogenic cell cultures. J Histochem Cytochem 2003;51:633-641.

De Oliveira PT, Nanci A. Nanotexturing of titanium-based surfaces upregulates expression of bone sialoprotein and osteopontin by cultured osteogenic cells. Biomaterials 2004;25:403-413.

De Oliveira PT, Zalzal SF, Beloti MM, Rosa AL, Nanci A. Enhancement of in vitro osteogenesis on titanium by chemically produced nanotopography. J Biomed Mater Res A 2007;80:554-564.

De Oliveira PT, de Oliva MA, Maximiano WM, Sebastião KE, Crippa GE, Ciancaglini $P$, Beloti MM, Nanci A, Rosa AL. Effects of a mixture of growth factors and proteins on the development of the osteogenic phenotype in human alveolar bone cell cultures. J Histochem Cytochem 2008;56:629-638.

Elias KL, Price RL, Webster TJ. Enhanced functions of osteoblasts on nanometer diameter carbon fibers. Biomaterials 2002;23:3279-3287. 
Francis-West $\mathrm{P}$, Abdelfattah $\mathrm{A}$, Chen $\mathrm{P}$, Allen $\mathrm{C}$, Parish $\mathrm{J}$, Ladher $\mathrm{R}$, Allen $\mathrm{S}$, MacPherson S, Luyten F, Archer C. Mechanisms of GDF-5 action during skeletal development. Development 1999;126:1305-1315.

Garcia AJ, Reyes CD. Bio-adhesive surfaces to promote osteoblast differentiation and bone formation. J Dent Res 2005;84:407-413.

Gregory CA, Gunn WG, Peister A, Prockop DJ. An Alizarin red-based assay of mineralization by adherent cells in culture: comparison with cetylpyridinium chloride extraction. Anal Biochem. 2004;329: 77-84.

Hovgaard MB, Rechendorff K, Chevallier J, Foss M, Besenbacher F. Fibronectin adsorption on tantalum: the influence of nanoroughness. J Phys Chem $B$. 2008;28:8241-8249

Irie K, Zalzal S, Ozawa H, McKee MD, Nanci A. Morphological and immunocytochemical characterization of primary osteogenic cell cultures derived from fetal rat cranial tissue. Anat Rec 1998;252:554-567.

Junker R, Dimakis A, Thoneick M, Jansen JA. Effects of implant surface coatings and composition on bone integration: a systematic review. Clin Oral Implants Res 2009;20 Suppl 4:185-206.

Khang D, Lu J, Yao C, Haberstroh KM, Webster TJ. The role of nanometer and submicron surface features on vascular and bone cell adhesion on titanium. Biomaterials 2008;29:970-983.

Kuniyasu $\mathrm{H}$, Hirose $\mathrm{Y}$, Ochi M, Yajima A, Sakaguchi K, Murata M, Pohl J. Bone augmentation using rhGDF-5-collagen composite. Clin Oral Implants Res 2003;14:490-499.

Le Guehennec L, Martin F, Lopez-Heredia MA, Louarn G, Amouriq Y, Cousty J, Layrolle P. Osteoblastic cell behavior on nanostructured metal implants. Nanomed 2008;3:61-71

Livak KJ, Schmittgen TD. Analysis of relative gene expression data using real-time quantitative PCR and the 2(-Delta Delta C(T)) Method. Methods. 2001;25:402-408.

Lord MS, Foss M, Besenbacher F. Influence of nanoscale surface topography on protein adsorption and cellular response. Nan. Tod. 2010;5,66-78. 
Lossdorfer S, Schwartz Z, Wang L, Lohmann CH, Turner JD, Wieland M, Cochran DL, Boyan BD. Microrough implant surface topographies increase osteogenesis by reducing osteoclast formation and activity. J Biomed Mater Res A 2004;3:361-369.

Lowry OH, Rosebrough NJ, Farr AL, Randall RJ. Protein measurement with the Folin phenol reagent. J Biol Chem 1951;193:265-275.

Lutz R, Srour S, Nonhoff J, Weisel T, Damien CJ, Schlegel KA. Biofunctionalization of titanium implants with a biomimetic active peptide (P-15) promotes early osseointegration. Clin Oral Implants Res 2010;21:726-734

Meirelles L, Arvidsson A, Albrektsson T, Wennerberg A. Increased bone formation to unstable nano rough titanium implants. Clin Oral Implants Res 2007;18:326-332.

Meirelles L, Arvidsson A, Andersson M, Kjellin P, Albrektsson T, Wennerberg A. Nano hydroxyapatite structures influence early bone formation. J Biomed Mater Res A 2008;87:299-307.

Mendelsohn R, Mao G, Flach CR. Infrared reflection-absorption spectroscopy: principles and applications to lipid-protein interaction in Langmuir films. Biochim Biophys Acta 2010;4:788-800.

Mendonça G, Mendonça DB, Aragão FJ, Cooper LF. Advancing dental implant surface technology - From micron- to nanotopography. Biomaterials 2008; 28:38223835.

Mendonça G, Mendonça DB, Simões LG, Araújo AL, Leite ER, Duarte WR, Cooper LF, Aragão FJ. Nanostructured alumina-coated implant surface: effect on osteoblastrelated gene expression and bone-to-implant contact in vivo. Int $\mathrm{J}$ Oral Maxillofac Implants 2009;24:205-215

Mendonça G, Mendonça DB, Aragão FJ, Cooper LF. The combination of micron and nanotopography by $\mathrm{H} 2 \mathrm{SO} 4 / \mathrm{H} 2 \mathrm{O} 2$ treatment and its effects on osteoblast-specific gene expression of hMSCs. J Biomed Mater Res A 2010;94:169-179.

Millán JL. Mammalian alkaline phosphatases: from biology to applications in medicine and biotechnology. Weinhein: Wiley VCH; 2006. 337 pp.

Morra M, Cassinelli C, Cascardo G, Cahalan P, Cahalan L, Fini M, Giardino R. Surface engineering of titanium by collagen immobilization. Surface characterization and in vitro and in vivo studies. Biomaterials 2003;24:4639-4654. 
Morra M. Biochemical modification of titanium surfaces: peptides and ECM proteins. Eur Cell Mater 2006;12:1-15.

Morra M. Biomolecular modification of implant surfaces. Expert Rev Med Devices 2007;4:361-372.

Mosmann T. Rapid colorimetric assay for cellular growth and survival: Application to proliferation and cytotoxicity assays. J Immunol Methods 1983;65:55-63.

Moy PK, Medina D, Shetty V, Aghaloo TL. Dental implant failure rates and associated risk factors. Int J Oral Maxillofac Implants 2005;20: 569-577.

Nakamura T, Yamamoto M, Tamura M, Izumi Y. Effects of growth/differentiation factor-5 on human periodontal ligament cells. J Periodontal Res 2003;38:597-605.

Nanci A, Zalzal S, Gotoh Y, McKee MD. Ultrastructural characterization and immunolocalization of osteopontin in rat calvarial osteoblast primary cultures. Microsc Res Tech 1996;33:214-231.

Nanci A, Wuest JD, Peru L, Brunet P, Sharma V, Zalzal S, McKee MD. Chemical modification of titanium surfaces for covalent attachment of biological molecules. $J$ Biomed Mater Res1998;40:324-335.

Nishitoh $\mathrm{H}$, Ichijo $\mathrm{H}$, Kimura $\mathrm{M}$ et al. Identification of type I and type II serine/ threonine kinase receptors for growth/ differentiation factor-5. J Biol Chem; 1996;271:21345-21352.

O'Toole GC, Salih E, Gallagher C, FitzPatrick D, O'Higgins N, O'Rourke SK. Bone sialoprotein-coated femoral implants are osteoinductive but mechanically compromised. J Orthop Res 2004;22:641-646.

Park JY, Gemmell CH, Davies JE. Platelet interactions with titanium: modulation of platelet activity by surface topography. Biomaterials 2001;22:2671-2682.

Price RL, Haberstroh KM, Webster TJ. Enhanced functions of osteoblasts on nanostructured surfaces of carbon and alumina. Med Biol Eng Comput 2003;41:372375. 
Price RL, Ellison K, Haberstroh KM, Webster TJ. Nanometer surface roughness increases select osteoblast adhesion on carbon nanofiber compacts. J Biomed Mater Res A 2004;70:129-138.

Puckett S, Pareta R, Webster TJ. Nano rough micron patterned titanium for directing osteoblast morphology and adhesion. Int J Nanomedicine 2008;3:229-241

Puleo DA, Nanci A. Understanding and controlling the bone-implant interface. Biomaterials 1999;20:2311-2321.

Rajaraman R, Rounds DE, Yen SP, Rembaum A. A scanning electron microscope study of cell adhesion and spreading in vitro. Exp Cell Res 1974;2:327-339.

Rammelt S, Schulze E, Bernhardt R, Hanisch U, Scharnweber D, Worch H, Zwipp H, Biewener A. Coating of titanium implants with type-I collagen. J Orthop Res 2004; 22:1025-1034.

Rezania A, Johnson R, Lefkow AR, Healy KE. Bioactivation of metal oxide surfaces. 1. Surface characterization and cell response. Langmuir 1999;15:6931-6939.

Richert L, Vetrone F, Yi J-H, Zalzal SF, Wuest JD, Rosei, Nanci A. Surface nanopatterning to control cell growth. Adv Mater 2008;15:1-5.

Richert L, Variola F, Rosei F, Wuest J, Nanci A. Adsorption of proteins on nanoporous Ti surfaces. Surf Sci 2010;604:1445-1451

Roessler S, Born R, Scharnweber D, Worch H, Sewing A, Dard M. Biomimetic coatings functionalized with adhesion peptides for dental implants. J Mater Sci Mater Med 2001;12:871-877.

Scharnweber D, Born R, Flade K, Roessler S, Stoelzel M, Worch H. Mineralization behaviour of collagen type I immobilized on different substrates Biomaterials 2004;25:2371-2380.

Scholzen T, Gerdes J. The Ki-67 protein: from the known and the unknown. J Cell Physiol 2000;182:311-322.

Schwartz Fo HO, Novaes AB Jr, de Castro LMS, Rosa AL, de Oliveira PT. In vitro osteogenesis on a microstructured titanium surface with additional submicron-scale topography. Clin Oral Implants Res 2007;18:333-344. 
Schwarz F, Wieland M, Schwartz Z, Zhao G, Rupp F, Geis-Gerstorfer J, Schedle A, Broggini N, Bornstein MM, Buser D, Ferguson SJ, Becker J, Boyan BD, Cochran DL. Potential of chemically modified hydrophilic surface characteristics to support tissue integration of titanium dental implants. J Biomed Mater Res B Appl Biomater 2009;88:544-557.

Schouten C, Meijer GJ, van den Beucken JJ, Spauwen PH, Jansen JA. Effects of implant geometry, surface properties, and TGF-beta1 on peri-implant bone response: an experimental study in goats. Clin Oral Implants Res 2009;20:421-429.

Shekaran A, Garcia AJ. Nanoscale engineering of extracellular matrix-mimetic bioadhesive surfaces and implants for tissue engineering. Biochim Biophys Acta. 2010 May 8. [Epub ahead of print].

Shimaoka H, Dohi Y, Ohgushi H, Ikeuchi M, Okamoto M, Kudo A, Kirita T, Yonemasu K. Recombinant growth/differentiation factor-5 (GDF-5) stimulates osteogenic differentiation of marrow mesenchymal stem cells in porous hydroxyapatite ceramic. J Biomed Mater Res A. 2004;68:168-176.

Spiro RC, Liu LS, Heidaran MA, Thompson AY, Ng, CK, Pohl J., Poser JW. Inductive activity of recombinant human growth and differentiation factor-5. Biochemical Society Transactions 2000;28:362-368.

Stein GS, Lian JB. Molecular mechanisms mediating proliferation/differentiation interrelationships during progressive development of the osteoblast phenotype. Endocr Rev 1993;14:424-442.

Susin C, Qahash M, Polimeni G, Lu PH, Prasad HS, Rohrer MD, Hall J, Wikesjö UM. Alveolar ridge augmentation using implants coated with recombinant human bone morphogenetic protein-7 (rhBMP-7/rhOP-1): histological observations. J Clin Periodontol 2010;37:574-581.

Tosatti S, Schwartz Z, Campbell C, Cochran DL, VandeVondele S, Hubbell JA, Denzer A, Simpson J, Wieland M, Lohmann CH, Textor M, Boyan BD. RGDcontaining peptide GCRGYGRGDSPG reduces enhancement of osteoblast differentiation by poly(L-lysine)-graft-poly(ethylene glycol)-coated titanium surfaces. J Biomed Mater Res A 2004;68:458-472.

Transferetti BC, Davanzo CU. Introdução às técnicas de reflexão especular e de reflexão-absorção no infravermelho: (2) reflexão-absorção. Quím Nova 2001;24:99104. 
van den Dolder J, Jansen JA. The response of osteoblast-like cells towards collagen type I coating immobilized by p-nitrophenylchloroformate to titanium. J Biomed Mater Res A 2007;83:712-719.

Variola F, Yi JH, Richert L, Wuest JD, Rosei F, Nanci A. Tailoring the surface properties of Ti6Al4V by controlled chemical oxidation. Biomaterials 2008;29:12851298.

Variola F, Vetrone F, Richert L, Jedrzejowski P, Yi JH, Zalzal S, Clair S, Sarkissian A, Perepichka DF, Wuest JD, Rosei F, Nanci A. Improving biocompatibility of implantable metals by nanoscale modification of surfaces: an overview of strategies, fabrication methods, and challenges. Small 2009;5:996-1006.

Vetrone F, Variola F, Tambasco de Oliveira P, Zalzal SF, Yi JH, Sam J, BombonatoPrado KF, Sarkissian A, Perepichka DF, Wuest JD, Rosei F, Nanci A. Nanoscale oxidative patterning of metallic surfaces to modulate cell activity and fate. Nano Lett 2009;9:659-665.

Webster TJ, Schadler LS, Siegel RW, Bizios R. Mechanisms of enhanced osteoblast adhesion on nanophase alumina involve vitronectin. Tissue Eng 2001;7:291-301.

Webster TJ, Ejiofor JU. Increased osteoblast adhesion on nanophase metals: Ti, Ti6Al4V, and CoCrMo. Biomaterials 2004;25:4731-4739.

Wieland M, Textor M, Chehroudi B, Brunette DM. Synergistic interaction of topographic features in the production of bone-like nodules on $\mathrm{Ti}$ surfaces by rat osteoblasts. Biomaterials 2005;26:1119-1130.

Wikesjö UM, Huang YH, Xiropaidis AV, Sorensen RG, Rohrer MD, Prasad HS, Wozney JM, Hall J. Bone formation at recombinant human bone morphogenetic protein-2-coated titanium implants in the posterior maxilla (Type IV bone) in nonhuman primates. J Clin Periodontol 2008;35:992-1000.

Yang L, Sheldon BW, Webster TJ. The impact of diamond nanocrystallinity on osteoblast functions. Biomaterials 2009;30:3458-3465

Yang GL, He FM, Hu JA, Wang XX, Zhao SF. Biomechanical comparison of biomimetically and electrochemically deposited hydroxyapatite-coated porous titanium implants. J Oral Maxillofac Surg 2010;68:420-427. 
Yao C, Slamovich EB, Webster TJ. Enhanced osteoblast functions on anodized titanium with nanotube-like structures. J Biomed Mater Res A 2008;85:157-166.

Yi J-H, Bernard C, Variola F, Zalzal SF, Wuest JD, Rosei F, Nanci A. Characterization of a bioactive nanotextured surface created by controlled chemical oxidation of titanium. Surf Sci 2006;60:4613-4621.

Yoshimoto T, Yamamoto $M$, Kadomatsu $H$, Sakoda $K$, Yonamine $Y$, Izumi $Y$. Recombinant human growth/differentiation factor-5 (rhGDF-5) induced bone formation in murine calvariae. J Periodontal Res 2006;41:140-147. 